\title{
Mechanism of replication fork reversal and protection by human RAD51 and RAD51 paralogs
}

Petr Cejka ( $\sim$ petr.cejka@irb.usi.ch )

Institute for Research in Biomedicine

Swagata Halder

University of Oxford

Aurore Sanchez

Institut Curie

\section{Lepakshi Ranjha}

Institute for Research in Biomedicine

\section{Angelo Taglialatela}

Columbia University Medical Center

Giordano Reginato

Institute for Research in Biomedicine Bellinzona

llaria Ceppi

Universita della Svizzera Italiana

\section{Ananya Acharya}

Universita della Svizzera Italiana

Roopesh Anand

Universita della Svizzera Italiana

Alberto Ciccia

Columbia University Medical Center https://orcid.org/0000-0003-4789-6564

\section{Article}

Keywords:

Posted Date: December 2nd, 2021

DOI: https://doi.org/10.21203/rs.3.rs-1096289/v1

License: (a) (i) This work is licensed under a Creative Commons Attribution 4.0 International License.

Read Full License 
1 Mechanism of replication fork reversal and protection by human RAD51 and RAD51 paralogs

2

3 Swagata Halder ${ }^{1}$, Aurore Sanchez ${ }^{1}$, Lepakshi Ranjha ${ }^{1}$, Angelo Taglialatela ${ }^{2}$, Giordano Reginato ${ }^{1,3}$, Ilaria Ceppi ${ }^{1,3}$, Ananya Acharya ${ }^{1,3}$, Roopesh Anand ${ }^{1}$, Alberto Ciccia ${ }^{2}$ and Petr Cejka ${ }^{1,3^{*}}$

5

6

$7 \quad{ }^{1}$ Institute for Research in Biomedicine, Università della Svizzera italiana (USI), Faculty of Biomedical 8 Sciences, Bellinzona, Switzerland

$9 \quad{ }^{2}$ Department of Genetics and Development, Herbert Irving Comprehensive Cancer Center, Columbia 10 University Irving Medical Center, New York, NY, USA.

$11{ }^{3}$ Department of Biology, Institute of Biochemistry, Eidgenössische Technische Hochschule (ETH), Zü12 rich, Switzerland

13

14

$15 *$ To whom correspondence should be addressed. Tel: +41 9182003 61; Fax: +41 9182003 05; Email: 16 petr.cejka@irb.usi.ch

17

18

19 
SMARCAL1, ZRANB3 and HLTF are all required for the remodeling of replication forks upon stress. Using reconstituted reactions, we show that the motor proteins have unequal biochemical capacities, explaining why they have non-redundant functions. Whereas SMARCAL1 uniquely anneals RPA-coated ssDNA, suggesting an initial function in fork reversal, it becomes comparatively inefficient in subsequent branch migration. We also show that low concentrations of RAD51 and the RAD51 paralog complex, RAD51B-RAD51C-RAD51D-XRCC2 (BCDX2), directly stimulate SMARCAL1 and ZRANB3 but not HLTF, providing a mechanism underlying previous cellular data implicating these factors in fork reversal. Upon reversal, RAD51 protects replication forks from degradation by MRE11, DNA2 and EXO1 nucleases. We show that the protective function of RAD51 unexpectedly depends on its binding to double-stranded DNA, and higher RAD51 concentrations are required for DNA protection compared to reversal. Together, we define the non-canonical functions of RAD51 and its paralogs in replication fork reversal and protection. 
51 Homologous recombination (HR) is one of the key cellular pathways required for the maintenance of genome stability. Historically, recombination proteins have been mostly studied in the context of DNA double-strand break (DSB) repair ${ }^{1,2}$. The first step in recombinational repair of broken DNA is DNA end resection, where specialized nucleases degrade 5'-terminated DNA strands at the DSB sites, leading to $3^{\prime}$ overhangs. Resection is typically initiated by the MRE11 nuclease acting within the MRE11RAD50-NBS1 (MRN) complex in conjunction with CtIP. The ensemble first nicks 5'-terminated DNA strand near the break end ${ }^{3}$. It has the unique capacity to nick past protein blocks, such as stalled topoisomerases or the Ku heterodimer, or past secondary DNA structures, which initiates processing of DNA breaks. The 3'-5' exonuclease of MRN is subsequently believed to degrade DNA between the nick sites and back towards the broken end, resulting in 3' overhangs of limited length ${ }^{4}$. The initial short-range resection by MRN-CtIP is in most cases extended by either of two long-range nucleases, EXO1 or DNA2, which functions together with the Bloom (BLM) or Werner (WRN) helicase ${ }^{5}$.

Downstream of resection in DSB repair, the ssDNA overhang is first coated by the single-strand DNA (ssDNA) binding protein Replication Protein A (RPA). In the next step, RPA is replaced by RAD51, a key recombinase in eukaryotic cells. The replacement of RPA and loading of RAD51 on the ssDNA overhang is facilitated by a group of proteins termed as recombination mediators, which include the BRCA2 protein, and the RAD51 paralog complexes, either RAD51B-RAD51C-RAD51D-XRCC2 (BCDX2), or RAD51C-XRCC3 (CX3) 1, 2, 7, 8 . These proteins catalyze the formation of the RAD51 nucleoprotein filament, which has the capacity to identify, pair, and invade homologous doublestranded DNA (dsDNA). In vegetative cells, the homologous DNA is typically the sister chromatid that carries the identical genetic sequence. Once the RAD51 nucleoprotein filament invades homologous DNA, the 3'-terminated end serves as a primer for DNA synthesis that recovers any missing genetic information near the break site. The joint molecule intermediates are subsequently matured and processed to yield two recombined molecules, thus restoring genome integrity in a largely error-free manner. The function of recombination factors in the context of DSB repair is now relatively well understood $^{1,2}$.

More recently, it has been discovered that several recombination proteins have separate DSB repairindependent functions in the response to replication stress ${ }^{9,10}$. When replicating damaged templates, repetitive DNA sequences or DNA at telomeres, during replication-transcription conflicts or upon the overexpression of oncogenes, the forks can uncouple and the leading strand polymerase may transiently stall $^{11}$. Upon prolonged stalling, depending on the cellular context, replication can restart by PRIMPOLmediated repriming, or the forks can undergo reversal ${ }^{12,13,14}$. Fork reversal involves annealing of the two nascent DNA stands yielding a 4-way junction, followed by branch migration ${ }^{15,16,17}$. In contrast to 
For a long time, fork reversal was thought to be only a pathological process ${ }^{18}$. More recent data however uncovered that depending on the context and cellular genetic background, fork reversal may be benefi$\operatorname{cial}^{15,16,19}$. Fork reversal may in fact limit the extent of ssDNA at stalled forks, provide cells time to deal with the respective challenge, and in this way prevent DNA breakage or even enables specific DNA repair. Indeed, several motor proteins with unique capacities to reverse replication forks have been identified, including but not limited to SMARCAL1, ZRANB3 and HLTF ${ }^{16,20}$. Depletion of SMARCAL1 and ZRANB3 results in sensitivity to conditions inducing replication stress and enhancing genome instability, indicating that fork reversal catalyzed by these enzymes in wild type cells can be a

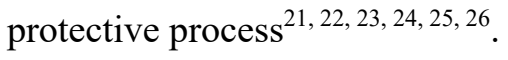

In certain conditions, uncoupling of leading and lagging strand DNA synthesis may result in the formation of ssDNA gaps, which together with aberrant fork reversal can lead to DNA degradation and genome instability. Gaps of ssDNA on newly synthesized daughter strand or on the apex of the reversed replication fork represent entry points for pathological nucleolytic degradation, unless stabilized by RAD51 $1^{10,16,27}$. The degradation of nascent DNA can be particularly observed in cells with impaired functions of BRCA1, BRCA2 and a growing number of additional factors, which are believed to recruit and stabilize RAD51 on DNA, or otherwise directly or indirectly inhibit the respective nucleases ${ }^{9,17,19}$, 28, 29. Remarkably, the same pro-DNA end resection nucleases that promote DSB repair, including MRE11 (presumably within the MRN complex), EXO1 and DNA2 were shown to contribute to the pathological nascent DNA degradation in various genetic backgrounds ${ }^{28,30,31,32,33,34}$. Notably, degradation of reversed forks by DNA2 in wild type cells may mediate fork restart ${ }^{35}$. The function of BRCA2 in fork protection is genetically separable from its function in DSB repair, showing that there are distinct mechanisms at play 9 . How RAD51 protects nascent DNA remains uncharacterized, but it has been assumed that RAD51 binding to ssDNA on the regressed arm of the reversed forks serves as a barrier against the entry of the resection nucleases ${ }^{16,27}$.

Cellular data suggest that the impaired RAD51 function to protect stalled forks in BRCA-deficient cells results in extended degradation of nascent DNA of multiple kilobases in length ${ }^{9}$. Such DNA degradation is dependent on the proteins implicated in fork reversal, including SMARCAL1, ZRANB3 and HLTF, which suggested that reversed, but not stalled replication forks are primarily subjected to degradation ${ }^{9}$ 27,30,31,36. However, nascent DNA degradation is not observed upon depletion of RAD51 itself $^{17,31}$. This apparently paradoxical observation was explained by a model where RAD51 also promotes fork reversal. Accordingly, in the absence of RAD51, the substrates for DNA degradation, i.e. reversed forks, are not formed. In the absence of the relevant substrate, the function of RAD51 in fork protection becomes irrelevant, explaining why nascent DNA is stable upon depletion of RAD51 ${ }^{17,37}$. The function of RAD51 in fork reversal, in contrast to DNA protection, is independent of BRCA2 ${ }^{9,31}$. How mechanistically RAD51 promotes replication fork reversal remains undefined, but it appears to be distinct from its function in canonical recombination ${ }^{38}$. Similarly as with BRCA2, the function of RAD51 in DSB 
121 repair and fork metabolism/modulation is genetically separable ${ }^{38}$. Recently, the BCDX2 RAD51 pa122 ralog complex was found to promote fork reversal alongside RAD51 in cellular assays ${ }^{39}$.

123 The seemingly paradoxical situation where RAD51 may both promote and prevent DNA degradation

124 highlights the difficulties explaining cellular phenotypes and thus warrants the need for a more direct

125 understanding of the underlying mechanisms ${ }^{37}$. Here we use reconstitution biochemistry, which allows

126 us to study elements of the reactions governing the metabolism of challenged replication forks in isola-

127 tion. We show that the fork remodelers SMARCAL1, ZRANB3 and HLTF have different substrate

128 preferences, suggesting that they may catalyze different reactions and thus act at distinct steps during

129 fork remodeling, explaining cellular data why these factors have non-redundant functions. We show

130 that RAD51 and the BCDX2 RAD51 paralog complex directly promote the motor-driven strand an-

131 nealing activity of SMARCAL1 and ZRANB3, which identifies the mechanism by which RAD51 and

132 BCDX2 may facilitate fork reversal. We show that compared to fork reversal, higher RAD51 concen-

133 trations are required for DNA protection against MRE11-RAD50 exonuclease, MRN endonuclease,

134 and EXO1 and DNA2 nucleases. In contrast to the current models, we demonstrate that the protective

135 function of RAD51 also involves its capacity to bind dsDNA. Together, our data provide comprehen-

136 sive insights into the mechanisms underlying the function of RAD51 and RAD51 paralogs in the me-

137 tabolism of challenged replication forks. 


\section{SMARCAL1, ZRANB3 and HLTF have unequal biochemical activities}

144 SMARCAL1, ZRANB3 and HLTF have all been implicated in replication fork reversal in vitro and in

$145 v i v o^{22,40,41}$. The loss of either of these enzymes was shown to abolish nascent DNA degradation in 146 BRCA1/2-deficient cells, suggesting that these factors may act in a non-redundant manner to promote 147 fork reversa $1^{19}$. To better understand the function of these fork remodelers, we expressed and purified 148 SMARCAL1, ZRANB3 and HLTF from insect Sf9 cells (Fig. 1a). All three translocases hydrolyzed 149 ATP, as expected, with SMARCAL1 showing the highest specific activity, followed by HLTF and 150 ZRANB3 (Supplementary Fig. 1a). We next set out to compare the relative activities of these motor proteins in biochemical assays mimicking elements of fork reversal. We first used oligonucleotidebased DNA substrates resembling stalled replication forks with ssDNA gaps either in the leading or the lagging DNA strand (Fig. 1b). We observed, as reported previously, that SMARCAL1 in the presence of the ssDNA binding protein RPA was more efficient on forks with leading strand gaps, as opposed to ZRANB3, which prefers RPA on lagging strand gaps ${ }^{42}$ (Fig. 1c). Using the leading strand gap substrate, SMARCAL1 was also more efficient than HLTF (Fig. 1c), while the three translocases exhibited similar specific activities on the lagging strand gap substrate (Fig. 1c). In contrast to the activities of SMARCAL1 and ZRANB3 that are regulated by RPA ${ }^{42}$, the function of HLTF was not RPA sensitive (Fig. 1d). During fork reversal, the initial annealing of the nascent DNA strands leads to the formation of a 4-way junction (Holliday junction, HJ), which is further branch migrated by the motor proteins,

161 leading to reversed forks of up to several kilobases in length ${ }^{16}$. Using a mobile HJ substrate to assay for 162 branch migration, we observed that SMARCAL1 was in contrast the least efficient enzyme, essentially 163 incapable of branch migration at physiological (150 mM) salt concentrations. However, under less re164 strictive conditions in lower salt, the branch migration activity of SMARCAL1 was readily detected 165 (Fig. 1f, right panel). Instead, both ZRANB3 and HLTF were highly and comparably efficient in branch migration at $150 \mathrm{mM}$ salt (Fig. 1e, f).

167 The activity of the SMARCAL1 and ZRANB3 enzymes was first analyzed by a topoisomerase-coupled assay that monitors the annealing of RPA-coated ssDNA bubbles in plasmid DNA, which can be observed as changes in DNA topology $y^{25,43,44}$. Such activity is thought to mimic the initial stages of fork remodeling. Both SMARCAL1 and ZRANB3 were shown to anneal the RPA-coated DNA bubbles as a result of their motor functions, as ATP hydrolysis is required for this reaction. However, the specific activities of SMARCAL1 and ZRANB3 have not been compared. We observed that SMARCAL1 was comparably efficient to ZRANB3, while HLTF showed much smaller capacity to anneal DNA in this assay (Fig. 1g, h). 
Taken together, our data indicate that SMARCAL1, ZRANB3 and HLTF possess quite different biochemical activities and substrate preferences. Our results support a model positing that fork reversal is not catalyzed by a single enzyme in a processive manner, but that it is rather a dynamic process that involves the sequential engagement of several factors.

\section{SMARCAL1 specifically anneals RPA-coated ssDNA}

Several helicases, such as members of the RecQ family, were reported to anneal two ssDNA molecules, but the reactions were inhibited by $\mathrm{RPA}^{45,46}$. Considering that cellular RPA concentration is thought to be sufficient to coat all ssDNA in most cases, the physiological relevance of these observations remains unclear. In this regard, the reported activities of the RecQ family members differ from the canonical RecO/RAD52 family annealing proteins, which anneal RPA-coated ssDNA to promote homologous recombination ${ }^{47,48}$. The observation that SMARCAL1 and ZRANB3 are efficient in annealing bubbled DNA coated with RPA prompted us to investigate whether the enzymes can anneal two ssDNA molecules similarly as RAD52. The annealing of the bubbled DNA in the topoisomerase-coupled assays could result from an annealing activity per se, or can be a consequence of the dsDNA translocase activity rezipping the bubble from the side. To distinguish between these two possibilities, we set to define the function of the fork remodelers in complementary ssDNA annealing. We observed that SMARCAL1, ZRANB3 and HLTF were all able to anneal free ssDNA, which can be explained by multiple ssDNA binding sites on a single enzyme or by enzyme oligomerization, which can bring multiple ssDNA molecules to close proximity, stimulating their annealing. However, in the presence of RPA, the ssDNA annealing by ZRANB3 and HLTF was strongly reduced, similarly as observed with the RecQ family helicases ${ }^{45}$. In contrast, ssDNA annealing by SMARCAL1 remained highly proficient in the presence of RPA (Fig. 2a, b, c). Unlike RPA, the ssDNA annealing capacity of SMARCAL1 was abrogated when the ssDNA was pre-coated with mitochondrial SSB, showing that the annealing of ssDNA by SMARCAL1 is allowed in the presence of RPA in a specific manner (Fig. 2d). The annealing activity of SMARCAL1 was also observed in the absence of ATP, or when using the motor-dead SMARCAL1 (D549A, E550A, SMARCAL1-HD) variant showing that this particular activity is not ATPase dependent (Supplementary Fig. 2a), as is the case of RAD52 ${ }^{48}$. Therefore, the annealing of two ssDNA molecules by SMARCAL1 mechanistically differs from the annealing of bubbled DNA in the topoisomerase coupled assays, which largely require ATP hydrolysis ${ }^{25,43,44}$.

\section{The N-terminal region of SMARCAL1 contains a previously defined RPA-binding site, the integrity of} which is required for the recruitment of SMARCAL1 to DNA damage sites, and to direct SMARCAL1 to substrates with RPA-coated ssDNA gaps ${ }^{21}$ (Fig. 2e). To test for the requirement for direct interaction between SMARCAL1 and RPA in ssDNA annealing, we expressed and purified SMARCAL1 $(\triangle N)$, lacking the RPA interaction domain (Fig. 2f). The truncated SMARCAL1 was fully proficient in DNA 
210 branch migration in the absence of RPA and identical to wild type SMARCAL1 as an ATPase (Sup-

211 plementary Fig. 2b, c). However, the mutant was inefficient in ssDNA annealing in the presence of

212 RPA, showing that the direct interaction of SMARCAL1 with RPA is essential for this activity (Fig.

$2132 \mathrm{~g}$ ). Our results reveal that SMARCAL1 possesses a strand annealing activity similar to that of the

214 RAD52 protein family, which also rely on specific interaction with RPA ${ }^{48}$. We suggest that such activity

215 may be employed during the very initial steps of fork reversal, when the daughter ssDNA molecules

216 are separated from the parental strands and anneal with each other. These results further underline the

217 mechanistic differences between the fork remodeling enzymes SMARCAL1, ZRANB3 and HLTF.

218

219

RAD51 and BCDX2 paralogs promote motor-driven strand annealing activity of SMARCAL1

220 and ZRANB3 but not HLTF

221 Challenged DNA replication forks may undergo reversal, and reversed replication forks must be subsequently protected by RAD51 to prevent pathological nascent DNA degradation ${ }^{9,10,15,16,49}$. However, RAD51, along with the RAD51 paralog BCDX2 complex, were also paradoxically implicated in promoting fork reversal, through a yet unknown mechanism ${ }^{17,39}$. To elucidate whether the function of RAD51 and the RAD51 paralogs in fork remodeling may be direct, we next expressed and purified RAD51 and the BCDX2 complex (Fig. 3a). The BCDX2 complex was obtained upon co-expression of all subunits, as the preparation of the individual proteins resulted in poor yields and solubility. The BCDX2 complex did not aggregate, bound ssDNA and very weakly hydrolyzed ATP, as observed previously (Supplementary Fig. 3a-d) ${ }^{50}$.

230 We next set out to test whether RAD51 and BCDX2 complex affect the strand annealing and motor activities of SMARCAL1. To this point, we used the established topoisomerase-coupled assay $25,43,44$.

232 Strikingly, we observed that low concentrations of RAD51 and the BCDX2 complex promoted bubbled

233 DNA annealing by SMARCAL1, while none of these co-factors had a notable capacity to mediate DNA 234 annealing per se without SMARCAL1, even at much higher concentrations (Fig. 3b, Supplementary 235 Fig. 3e, f). Additionally, controls where no ATP was used or helicase-dead SMARCAL1 variant re236 placed the wild type protein largely abolished DNA annealing, indicating that a large proportion of the 237 relaxed DNA signal in the assay can be linked to the ATP hydrolysis-driven translocation activity of 238 SMARCAL1 (Fig. 3b, Supplementary Fig. 3g). Similarly to SMARCAL1, we observed that RAD51 239 and the BCDX2 paralogs promoted the annealing capacity of ZRANB3. As above with SMARCAL1, 240 we observed that RAD51 and BCDX2 could both promote ZRANB3 independently of each other (Fig. $2413 \mathrm{c}$ ). Only limited changes in DNA topology were observed when using helicase-dead ZRANB3 and all 242 co-factors, demonstrating that the majority of the signal in the assay can be linked to the motor activity of ZRANB3 leading to DNA annealing (Supplementary Fig. 3h). 
244 Differently from SMARCAL1 and ZRANB3, HLTF was not stimulated by either RAD51 or BCDX2 245 (Fig. 3d). The RAD51C-XRCC3 (CX3) complex could also promote DNA annealing with both 246 SMARCAL1 and ZRANB3 (Supplementary Fig. 3i, j, k), despite it has not been found to promote fork 247 reversal in vivo ${ }^{39,51}$. While the CX3 complex may not be efficiently recruited to physiological substrates 248 in cells, the experiments were informative as they revealed that the critical component of the paralogs 249 may be RAD51C, which is present in both BCDX2 and CX3 complexes. Together, we show that 250 RAD51 and BCDX2 promote the translocation-driven annealing of RPA-coated bubbled DNA by SMARCAL1 and ZRANB3, suggesting that the co-factors may have a direct role in fork reversal to stimulate the DNA translocases.

\section{SMARCAL1 and ZRANB3 physically interact with RAD51 and BCDX2}

To test whether the functional interplay between SMARCAL1 and ZRANB3 with RAD51 and BCDX2 may involve direct physical interactions, we immobilized RAD51 and performed pulldown experiments with the co-factors. We observed that BCDX2 interacted with RAD51 (the RAD51B component was detected), as described previously ${ }^{52}$. Importantly, we found that both SMARCAL1 and ZRANB3 also interacted with RAD51 (Fig. 4a). We next immobilized the BCDX2 complex, and observed a direct interaction with SMARCAL1 and ZRANB3, as detected by Western blotting and silver staining (Fig. $4 b, c)$. These results collectively suggest that the interplay of SMARCAL1 and ZRANB3 with RAD51 and BCDX2 likely involves direct physical interactions.

\section{Point mutation in SMARCAL1 disrupts physical and functional interactions with RAD51}

We next set out to define motifs in SMARCAL1 and ZRANB3 that mediate the interactions with RAD51 and BCDX2. We failed to identify an interaction motif with BCDX2, but we found regions in SMARCAL1 mediating the binding to RAD51. Physical and functional interactions between RAD51 and many of its co-factors, such as BRCA2, BARD1, MMS22L, RECQL5, SWSAP1 and FINGL1 are mediated by the FXXA motif $53,54,55,56,57,58$. We identified such a motif in SMARCAL1, which is conserved in evolution (Fig. 4d, Supplementary Fig. 4a). The FXXA motif is positioned ahead of the conserved $\alpha$ I SNF2 family ATPase domain (Supplementary Fig. 4b). The mutation of phenylalanine 446 into alanine (F446A) in SMARCAL1 disrupted the physical interaction with RAD51 (Fig. 4e, f). In contrast, disruption of F439, which is part of a less conserved FXXA sequence in human SMARCAL1 upstream of F446, did not impair the interaction (Fig. 4f , Supplementary Fig. 4a). We note that SMARCAL1 F446A variant per se was very similar to wild type SMARCAL1 in its fork reversal and ATPase capacities in vitro and retained its physical interaction with the BCDX2 complex 
SMARCAL1 ahead of the ATPase domain. The phenylalanine however does not conform to the FXXA motif, and the F47A substitution mutant retained its capacity to interact with RAD51 and was impaired in its ATPase activities (Supplementary Fig. 4e-h). We next found that mutation F736A in ZRANB3 disrupted interaction with RAD51, however it is likely that the mutation affected the fold of the substrate recognition domain, as it likewise abolished the biochemical activities of ZRANB3 and may thus not represent a direct interaction motif (Supplementary Fig. 4i-k) ${ }^{59}$. Due to the impact of this mutation on the activities of ZRANB3 per se, we could not test for the physiological relevance of the interaction with RAD51.

To investigate the physiological relevance of the disrupted physical interaction between SMARCAL1 and RAD51, we used MCF10A SMARCAL1-KO cells ${ }^{36}$, which were complemented with either wild type SMARCAL1 or the F446A variant (Fig. 4h). Following replication stress induced by hydroxyurea, it was previously demonstrated that SMARCAL1-mediated fork reversal can lead to nascent DNA degradation, as long as the nascent DNA is not protected by RAD51 ${ }^{36}$. The nascent DNA degradation is evident in cells lacking BRCA1 or BRCA2, which may be required to recruit, load or stabilize RAD51. In agreement with previous data ${ }^{36}$, we observed extensive nascent DNA degradation in BRCA1depleted SMARCAL1 KO cells reconstituted with wild type SMARCAL1 (Fig. 4h). In contrast, such extensive DNA degradation was not observed in BRCA1-depleted SMARCAL1 KO cells reconstituted with empty vector (no SMARCAL1), and it was partially attenuated in cells with SMARCAL1 F446A, which was expressed at levels comparable to wild type (Supplementary Fig 41). Taking into consideration that nascent DNA degradation in BRCA-deficient cells requires the fork reversal activity of SMARCAL1 ${ }^{36}$, our results suggest that SMARCAL1 F446A, which does not interact with RAD51, might display a defective fork reversal activity in mammalian cells.

High concentrations of RAD51 protect DNA from degradation by MRE11, EXO1 and DNA2 nucleases

In homologous recombination, the processing of DSBs is initiated by short-range resection that involves the endo- and exonuclease activities of MRN and CtIP, followed by the long-range pathways catalyzed by EXO1 and/or DNA2-BLM/WRN ${ }^{4,56}$. The same nucleolytic pathways were shown to degrade nascent DNA at stalled replication forks, with relative contributions of the nucleases dependent on conditions and genetic background $9,27,30,32,34,35$. To investigate the function of RAD51 in DNA protection, we reconstituted DNA end resection reactions without or with various concentrations of RAD51. We observed that RAD51 inhibited all DNA end resection reactions tested, including the exonuclease ac-

311 lated CtIP (Fig. 5a-e), and the long-range pathways of EXO1 and DNA2-WRN (Fig 5f-k). These ex-

312 periments allowed us to make several conclusions. 
313 First, higher RAD51 concentrations were in general required for DNA protection compared to motor-

314 driven strand annealing. Approximately $300 \mathrm{nM}$ to low micromolar RAD51 was required for a robust

315 protection against nucleolytic degradation, depending on the substrate and the respective nuclease ana-

316 lyzed. The RAD51 concentrations required for the inhibition of the endonuclease of MRN-CtIP were

317 similar to those required to inhibit the nonspecific NspI endonuclease, which may be used as a read-out

318 for RAD51 filament formation (Fig. 5a, b and Supplementary Fig. 5a). These results suggest that effi-

319 cient inhibition of DNA end resection occurs under conditions permissive for stable RAD51 filament

320 formation.

321 Second, the DNA affinity of RAD51 directly corresponds to its efficacy in inhibiting DNA degradation.

322 To this point, we used the RAD51 variants that differ in their capacity to bind DNA ${ }^{61,62,63}$. The tightly

323 binding RAD51-KR mutant generally inhibited resection more efficiently than wild type RAD51, while

324 the poorly DNA binding RAD51 variants KA, YA and TP were largely deficient in protection (Fig. 5a-

$325 \mathrm{~d}, \mathrm{~h}, \mathrm{i})$. Furthermore, the affinity of RAD51 to DNA depends on the presence of ATP. ATP binding

326 stimulates DNA binding by RAD51, while ATP hydrolysis leads to RAD51 dissociation from DNA ${ }^{61}$.

327 Correspondingly, the highest DNA binding affinity of RAD51 is observed in buffers with the non-

328 hydrolysable ATP analog ATP- $\gamma$-S. In accord with the modulation of DNA binding affinity of RAD51

329 by the nucleotide co-factors, we observed the strongest DNA protection by RAD51 when reactions

330 contained ATP- $\gamma$-S, followed by ATP, and the weakest protection in reactions lacking ATP (Fig. 5e-g).

331 These latter experiments could only be performed with resection nucleases that do not require ATP,

332 such as the exonuclease of MR and the exonuclease of EXO1.

333 Third, we did not find any apparent specific functional interactions between RAD51 and the DNA end 334 resection nucleases. To this point, we compared the capacity of human and yeast RAD51/Rad51 to 335 protect DNA against the human and yeast resection nucleases and nuclease complexes (Supplementary 336 Fig. 5b-h). We observed that human RAD51 was generally more efficient than yeast Rad51, which may 337 suggest some degree of specificity. However, human RAD51 was also more efficient in protecting DNA 338 against non-specific nucleases Exo-III and NspI (Supplementary Fig 5i, j). These experiments sug339 gested that the higher efficacy of human RAD51 compared to yeast Rad51 to protect DNA is not due 340 to specific functional interactions between human RAD51 and the nuclease complexes, but may be 341 rather due to a higher DNA affinity or protection capacity of human RAD51 per se.

The function of RAD51 in DNA protection corresponds to its capacity to bind double-stranded DNA

345 BRCA2 is required for nascent DNA protection by RAD51. Interestingly, the regions of BRCA2 required for DNA protection are distinct from those needed for homologous recombination and RAD51 loading onto RPA-coated ssDNA ${ }^{9}$. The BRCA2 BRC repeats are needed for homologous 
recombination, and in biochemical assays they were shown to enhance the binding of RAD51 to RPAcoated ssDNA, while they reduce the capacity of RAD51 to bind dsDNA ${ }^{9,64,65}$. The BRC repats are however not involved in DNA protection upon replication stress. Rather, the C-terminal RAD51 binding site is required for DNA protection ${ }^{9}$. The biochemistry of the C-terminal site is less understood, but it was demonstrated that it facilitates RAD51 binding also to dsDNA ${ }^{66}$. These results prompted us to investigate whether RAD51 binding to ssDNA overhangs at DNA ends, as indicated in current models ${ }^{16}$, indeed explains its protection function.

To investigate whether RAD51 binding to ssDNA or dsDNA explains its function in DNA protection, we prepared blunt-ended, 5'-overhanged and 3'-overhanged substrates. The MR exonuclease was inhibited by RAD51 to the same extent irrespectively of the presence of the overhang (Fig. 6a, b). This showed that the overhang is not required to assure protection against MRE11, and infers that the protection is instead dependent on RAD51 binding to the dsDNA part of the substrate. The same result was observed with EXO1. Although EXO1 shows a clear preference to process 5'-recessed strands and is least efficient on $5^{1}$-overhangs ${ }^{67}$, RAD51 inhibited DNA degradation to a similar extent with all structures tested (Fig. 6c, d), suggesting that overhang is not needed for protection. Likewise, the MRN-CtIP endonuclease clips dsDNA, and we showed that a variety of protein blocks promote such activity, as long as the blocks are located at DNA ends or DNA overhangs. Our observation that RAD51 blocks the MRN-CtIP endonuclease (Fig. 5a, b) again suggests that the inhibitory function is caused by RAD51 binding to dsDNA. Together, these results demonstrate that the binding of RAD51 to dsDNA is responsible for its inhibitory effect on the resection nucleases, at least in vitro. We show that the function of RAD51 to protect DNA from nucleolytic degradation is structural, and directly corresponds to the affinity of RAD51 to bind dsDNA. Tightly-bound RAD51 filaments then serve as a non-specific barrier against DNA degradation. Our results challenge the current model suggesting that the binding of RAD51 to ssDNA overhangs at the apex of the reversed fork structure explains its function in protection $^{16,27,67}$. Our data instead suggest that the capacity of RAD51 to bind dsDNA is relevant for its function in DNA protection, which is ultimately responsible for the maintenance of genome stability during replication stress (Fig. 7).

\section{DISCUSSION}

377 Here we used biochemistry to study the function of the replication fork remodelers SMARCAL1, 378 ZRANB3 and HLTF, their regulation by RAD51 and RAD51 paralogs, as well the interplay of RAD51 379 with nucleases implicated in pathological DNA degradation upon replication stress. 
Depletion of either SMARCAL1, ZRANB3 or HLTF brings about a profound defect in replication fork reversal, as observed by electron microscopy, or by proxy methods scoring for e.g., nascent DNA degradation in various genetic backgrounds upon stress ${ }^{19,22,40,41,68,69}$. To better define the function of fork remodelers, we compared here the specific activities of the fork remodelers on various substrates mimicking elements of fork reversal. We observed that SMARCAL1, but not ZRANB3 or HLTF, has a unique capacity to anneal RPA-coated ssDNA, a function reminiscent of the RAD52 protein family. The annealing function of SMARCAL1 depends on the RPA interaction motif within the N-terminus of SMARCAL1. We hypothesize that such annealing function might be relevant during the initial annealing of the displaced daughter strands during the early steps of fork reversal. The annealing activity of SMARCAL1, similarly to RAD52, does not involve ATPase activity. Previously, the function of SMARCAL1 and ZRANB3 was monitored in assays scoring for the annealing of bubbled DNA within circular plasmid. Such activity, in contrast to annealing of RPA-coated ssDNA oligonucleotides, is dependent on the motor activities of the remodelers. We show that in contrast to SMARCAL1 and ZRANB3, which had similar activities, HLTF was largely inactive in this assay.

Using oligonucleotide-based substrates mimicking fork reversal, it has been previously reported that SMARCAL1 and ZRANB3 have opposing preferences with respect to whether RPA is located on the leading or the lagging DNA strand ${ }^{42}$. We show that in contrast, the activity of HLTF does not appear to be affected by RPA. In branch migration, using 4-way junction substrates without ssDNA, HLTF and ZRANB3 were the most active enzymes, while SMARCAL1 was the least efficient. Our experiments demonstrated that the fork remodelers possess quite different specific activities with respect to the substrates used. The data support model where fork remodeling is not catalyzed by a single enzyme in a processive manner, but it is rather a process with various remodelers acting in a distributive manner, depending on the nature of the DNA intermediate and the substrate preference of the respective remodeler. Such model would explain the non-redundant relationship of remodeler in fork reversal ${ }^{36,69,70}$. translocases

Previous cellular data suggested that RAD51 and the BCDX2 complex promote fork reversal, but the underlying mechanism was not clear ${ }^{17,39}$. The function of RAD51 in fork remodeling was shown to be genetically separable and thus different from its canonical role in homologous recombination. Specifically, the strand exchange function of RAD51 was dispensable, pointing at a potential structural func-

413 tion $^{38}$. We show here that RAD51 and the RAD51 BCDX2 paralog complex stimulate the strand an414 nealing and branch migration activities of SMARCAL1 and ZRANB3, two of the key enzymes impli415 cated in fork reversal. SMARCAL1 and ZRANB3 were stimulated when RAD51 concentration was too low to support a nucleoprotein filament formation. 
417 In accord with a recent cellular study that identified a function of BCDX2 in promoting fork reversal ${ }^{39}$, 418 we find that the paralog complex also directly stimulates SMARCAL1 and ZRANB3. Unexpectedly, 419 RAD51 and BCDX2 stimulated SMARCAL1 and ZRANB3 independently of each other, as we ob420 served mostly additive effects when combined. The function of the RAD51 paralogs, such as the 421 BCDX2 complex, in homologous recombination remains poorly defined. Some reports suggest a joint 422 function for the paralogs and RAD51. Specifically, BCDX2 was shown to have a classical recombina423 tion mediator function to load RAD51 on RPA-coated ssDNA ${ }^{6}$ to remodel RAD51 filaments for acti424 vation $^{71}$, or to make them more resistant against disruption ${ }^{72}$. However, RAD51-independent function 425 of the RAD51 paralogs were also identified in cellular studies, such as in the single-strand annealing 426 pathway of DSB repair ${ }^{73}$, and BCDX2 was also found to physically and functionally associate with the 427 HELQ helicase ${ }^{74}$. The function of BCDX2 to promote SMARCAL1/ZRANB3 described here in vitro 428 also does not require RAD51.

The interplay of RAD51 and paralogs in promoting SMARCAL1 and ZRANB3 involves physical interactions

RAD51 and BCDX2 did not stimulate HLTF, a third enzyme shown to catalyze fork reversal, suggesting a specificity in the interplay of SMARCAL1 and ZRANB3 with RAD51 and BCDX2. In accord, we found that RAD51 and BCDX2 physically interact with SMARCAL1 and ZRANB3. We could then map the RAD51 interaction site in SMARCAL1 and constructed a single point mutant (SMARCAL1F446A) that disrupted the physical interaction with RAD51. The SMARCAL1 mutant was not impaired in its activities per se, but was deficient in promoting nascent DNA degradation in BRCA1-deficient cells, a process that requires the fork reversal activity of SMARCAL1, supporting the idea that the identified interplay of SMARCAL1 and RAD51 is physiologically relevant.

\section{The function of RAD51 in DNA protection is largely non-specific}

442 Downstream of fork reversal, RAD51 protects nascent DNA from degradation against nucleases. We 443 reconstituted both the endo- and exonuclease activities of MRE11, as well as EXO1 and DNA2, which 444 were all implicated in nascent DNA degradation, depending on the cellular background. We then tested 445 for the effect of RAD51 on the individual nucleolytic pathways and observed that RAD51 inhibited 446 them all to a similar extent. The level of inhibition was comparable when we used other non-cognate 447 yeast or bacterial nucleases. Interestingly, human RAD51 was somewhat more efficient in DNA pro448 tection compared to yeast Rad51, but this difference was observed in conjunction with both the cognate 449 human as well as with the non-specific nucleases, suggesting that there is no apparent functional inter450 action between RAD51 and the resection nucleases. RAD51 therefore inhibits DNA degradation in a 
largely non-specific manner, as a physical barrier on DNA. The concentrations of RAD51 required for

452 DNA protection were higher than those promoting fork remodeling, in accord with cellular data ${ }^{75}$. DNA 453 protection assays with RAD51 and non-specific nucleases are used as a proxy for RAD51 filament 454 formation. Therefore, we conclude that RAD51 filament formation is likely prerequisite for DNA protection.

\section{RAD51 protects nascent DNA upon binding to dsDNA}

458 Contrary to current models, we provide evidence that the binding of RAD51 to dsDNA (as opposed to ssDNA) may be crucial for its function in DNA protection (Fig. 7). Eukaryotic RAD51 has a similar affinity to both ssDNA and dsDNA ${ }^{61,76,77}$. In homologous recombination, RAD51 needs to bind ssDNA to form an active nucleoprotein filament. The binding of RAD51 to dsDNA is instead inhibitory, and several recombination factors facilitate RAD51 binding specifically to ssDNA ${ }^{57,65,77,78}$. The physiological relevance of the high affinity RAD51 binding to dsDNA is not known. The strong dsDNA binding capacity of eukaryotic RAD51 is somewhat paradoxical, because $E$. coli's RecA binds preferentially to ssDNA, demonstrating that stable dsDNA binding is not strictly associated with DNA strand exchange activity $^{77,78}$. Because of the recombination paradigm, but largely without direct evidence, it has been assumed that RAD51 binding to ssDNA at the apex of the reversed fork is responsible for DNA protection $^{16,27}$. Our data challenge this model, and instead suggest that RAD51 binding to the dsDNA part of the reversed fork is primarily responsible for its protection capacity.

We showed that the MRE11-RAD50 or EXO1 exonucleases were inhibited by RAD51 to a similar extent when using blunt-ended dsDNA or overhanged substrates, demonstrating directly that the presence of the overhang was not relevant for protection, at least in the reconstituted assay. RAD51 binding to dsDNA also fully explains its protective function against the MRN-CtIP endonuclease ensemble. MRN-CtIP only nicks dsDNA, even on overhanged substrates ${ }^{3,79}$. Binding of proteins to overhangs, including non-cognate factors such as streptavidin, is not inhibitory for MRN-CtIP ${ }^{79}$. RAD51 however clearly inhibits the MRN-CtIP endonuclease when using blunt-ended dsDNA, suggesting that dsDNA is the relevant substrate for RAD51 binding with respect to its protective function. We therefore propose that RAD51 inhibits the resection nucleases due to its binding to dsDNA. This model better explains the protective function of RAD51 in vivo, as it applies for reversed forks with any type of DNA structure at the end of the reversed arm, and does not rely on the presence of an overhang to mediate DNA protection. Electron microscopy analyses revealed that the regressed arms of the reversed forks are mostly composed of dsDNA, irrespectively of the conditions tested ${ }^{17}$. Cell-based assays further indicated that fork degradation can reach multiple kilobases in length, which goes beyond the length of the regressed arm of the reversed fork ${ }^{17,31}$. Therefore, dsDNA is clearly being degraded at challenged rep- 
486 One of the best-known co-factors of RAD51 in DNA protection is BRCA2. BRCA2 functions as a

487 recombination mediator in homologous recombination to load RAD51 on RPA-coated ssDNA, and 488 additionally has the capacity to channel RAD51 to ssDNA away from dsDNA ${ }^{64,65}$. This particular pro489 recombination function depends on the BRC repeats of BRCA2, and could be largely recapitulated with 490 only the short BRC4 peptide ${ }^{65}$. However, the BRC repeats of BRCA2, despite being essential for ho491 mologous recombination, are dispensable for fork protection ${ }^{9}$. Instead, the protective function of 492 BRCA2 depends on its C-terminal RAD51 binding site ${ }^{9}$. Strikingly, this site was previously demon493 strated to strongly facilitate RAD51 binding to dsDNA ${ }^{66}$. How the site affects ssDNA versus dsDNA 494 binding is not known. The capacity of the BRCA2 C-terminus to promote RAD51 binding to dsDNA 495 thus also agrees with our direct observation that RAD51 binding to dsDNA is critical for DNA protec496 tion in vitro. A number of additional factors including BRCA1 are also required for DNA protection ${ }^{80}$. 497 Whether they affect RAD51 binding to dsDNA, or facilitate DNA protection because of a different 498 mechanism, such as upon RAD51-independent DNA binding or through a direct inhibition of the nu499 cleases, remains an interesting area of investigation for future studies. Together, our data suggest that 500 the dsDNA binding capacity of RAD51 may have evolved in conjunction with its function to prevent 501 pathological DNA degradation at the replication fork. 
Human SMARCAL1, ZRANB3. Recombinant FLAG-SMARCAL1, FLAG-ZRANB3 and their variants were expressed in insect Spodoptera frugiperda 9 (Sf9) cells and purified by affinity chromatography, using pFastBac-FLAG-SMARCAL1 and pFastBac-FLAG-ZRANB3 expression constructs ${ }^{22}$.

510 Point mutagenesis of the corresponding DNA sequences was carried out by QuikChange II site-directed mutagenesis kit (Agilent Technologies), and the proteins were expressed and purified similarly as the wild type counterparts. Primers used for cloning and mutagenesis are listed in Table S1.

514 Human HLTF. The HLTF sequence was codon-optimized for $S f 9$ insect cells and synthesized by Syn515 bio Technologies, and cloned using NheI and XmaI sites (New England Biolabs) into pFB-2xMBP516 CtIP-His ${ }^{81}$ to create pFB-2xMBP-HLTFco-His, replacing the CtIP sequence with that of HLTF. The 517 bacmids and baculoviruses were prepared according to manufacturer's instructions (Bac-to-Bac system, 518 Life Technologies). Sf9 cells were transfected using a Trans-IT insect reagent (Mirus Bio). For protein production, Sf9 insect cells were seeded at $0.5 \times 10^{6}$ cells per $\mathrm{ml} 16$ hours before infection. The cells were then infected with respective baculoviruses and incubated for 52 hours at $27{ }^{\circ} \mathrm{C}$ with constant agitation. Cells were harvested (500 g, 10 minutes) and washed once with ice cold Phosphate buffer saline (PBS). The cell pellets were snap frozen in liquid nitrogen and stored at $-80{ }^{\circ} \mathrm{C}$. All the subsequent steps were carried out on ice or at $4{ }^{\circ} \mathrm{C}$. The pellets were resuspended and incubated for 20 minutes with continuous stirring in 3-volumes of lysis buffer $(50 \mathrm{mM}$ Tris- $\mathrm{HCl} \mathrm{pH} 7.5,1 \mathrm{mM}$ dithiothreitol [DTT], $5 \mathrm{mM}$ beta-mercaptoethanol [ $\beta-\mathrm{ME}], 1 \mathrm{mM}$ phenylmethylsulfonyl fluoride [PMSF], 1:400 [v/v] protease inhibitor cocktail [Sigma, P8340], $30 \mu \mathrm{g} / \mathrm{ml}$ leupeptin [Merck]). Next, 50\% glycerol was added to reach a final concentration of $\sim 16 \%$ to the cell extract, followed by $6.5 \%$ volume of $5 \mathrm{M} \mathrm{NaCl}$ (final concentration $305 \mathrm{mM}$ ), and further incubated for 30 minutes with continuous stirring. The cell suspension was centrifuged for 30 minutes at $48,000 \mathrm{~g}$ to obtain soluble extract. The supernatant was transferred to tubes containing pre-equilibrated amylose resin (New England Biolabs, $4 \mathrm{ml}$ per liter of $S f 9$ culture) and incubated for 1 hour with continuous rotation. The resin was collected by spinning at 2,000 g for 2 minutes and washed extensively batch-wise and also on a disposable $10 \mathrm{ml}$ column (ThermoFisher) with amylose wash buffer (50 mM Tris- $\mathrm{HCl} \mathrm{pH} \mathrm{7.5,} 5 \mathrm{mM} \beta$-ME, $1 \mathrm{mM}$ PMSF, 10\% glycerol, $1 \mathrm{M} \mathrm{NaCl}$ ). The final wash was performed at $300 \mathrm{mM} \mathrm{NaCl}$. Protein was eluted with amylose elution buffer (50 mM Tris-HCl pH 7.5, $5 \mathrm{mM} \beta$-ME, $1 \mathrm{mM}$ PMSF, 10\% glycerol, $300 \mathrm{mM} \mathrm{NaCl}, 10$ $\mathrm{mM}$ maltose [Sigma]) and the total protein concentration was estimated by Bradford assay. To cleave off the maltose-binding protein (MBP) tag, 1/6 (w/w) of PreScission Protease, with respect to total protein concentration in the eluate, was added and incubated for 1 hour at $4{ }^{\circ} \mathrm{C}$. The sample was then 
supplemented with $10 \mathrm{mM}$ imidazole and further passed through pre-equilibrated (amylose elution buffer supplemented with $10 \mathrm{mM}$ imidazole) Ni-NTA agarose resin (Qiagen) on a disposable column for 1 hour in flow. The Ni-NTA resin was washed 4-times with Ni-NTA wash buffer ( $50 \mathrm{mM}$ Tris-HCl $\mathrm{pH}$ 7.5, $5 \mathrm{mM} \beta$-ME, $1 \mathrm{M} \mathrm{NaCl}, 10 \%$ glycerol, $1 \mathrm{mM}$ PMSF, $40 \mathrm{mM}$ imidazole). Prior to elution, the protein was washed once with the same Ni-NTA wash buffer as above but with $150 \mathrm{mM} \mathrm{NaCl}$. Protein was eluted in the same buffer supplemented with $300 \mathrm{mM}$ imidazole, and subsequently dialyzed (50 $\mathrm{mM}$ Tris- $\mathrm{HCl} \mathrm{pH}$ 7.5, $5 \mathrm{mM} \beta$-ME, $100 \mathrm{mM} \mathrm{NaCl}, 10 \%$ glycerol, $0.5 \mathrm{mM}$ PMSF), sub-aliquoted, snap frozen and stored at $-80^{\circ} \mathrm{C}$ for later use.

Human RAD51 paralogs BCDX2 and CX3. Sequences for human RAD51 paralogs (RAD51B, RAD51C, RAD51D, XRCC2 and XRCC3) were codon-optimized for expression in Sf9 cells and synthetized by Synbio Technologies. FLAG-RAD51B and 10xHis-RAD51C were cloned into a pFB dual expression vector (ThermoFisher). The multiple cloning site 1 was utilized for FLAG-RAD51B using BamHI and NotI cloning sites and the multiple cloning site 2 was used for 10xHis-RAD51C employing the XmaI and NheI restriction sites, to create pFB-FLAG-RAD51Bco-10xHis-RAD51Cco. RAD51D and XRCC2 were similarly cloned into the same sites, respectively, to obtain pFB-RAD51DcoXRCC2co. XRCC3 was synthesized as BamHI-FLAG-XRCC3-NotI and cloned into the above vector to remove the RAD51B sequence to obtain pFB-FLAG-XRCC3co-10xHis-RAD51Cco. Baculoviruses expressing RAD51B-RAD51C, RAD51D-XRCC2 and XRCC3-RAD51C were prepared separately and $S f 9$ cells were co-infected with optimized ratios for these viruses to express the BCDX2 complex as a heterotetramer and the CX3 complex as a heterodimer. Both the complexes were purified in an identical manner using affinity chromatography. Cells were harvested 52 hours post infection, washed once with cold PBS, and the pellets were frozen in liquid nitrogen and stored at $-80{ }^{\circ} \mathrm{C}$ until further use. The subsequent steps were carried out on ice or at $4{ }^{\circ} \mathrm{C}$. The cell pellet was resuspended in lysis buffer (50 mM Tris-HCl pH 7.5, 2 mM $\beta$-ME, 1:400 [v/v] protease inhibitor cocktail [Sigma], $1 \mathrm{mM}$ PMSF, $30 \mu \mathrm{g} / \mathrm{ml}$ leupeptin (Merck), $20 \mathrm{mM}$ imidazole) for 20 minutes. Then, 50\% glycerol was added to a final concentration of $\sim 16 \%$, followed by $5 \mathrm{M} \mathrm{NaCl}$ to a final concentration of $305 \mathrm{mM}$. The suspension was incubated for additional 30 minutes with gentle agitation. The total cell extract was centrifuged at $48,000 \mathrm{~g}$ for 30 minutes to obtain soluble extract. The extract was then bound to Ni-NTA resin (Qiagen) for 1 hour batch wise followed by extensive washing with Ni-NTA wash buffer (50 mM Tris-HCl pH 7.5, $2 \mathrm{mM} \beta$-ME, $300 \mathrm{mM} \mathrm{NaCl}, 10 \%$ glycerol, $1 \mathrm{mM}$ PMSF, $10 \mu \mathrm{g} / \mathrm{ml}$ leupeptin, $20 \mathrm{mM}$ imidazole) both batch wise and on a disposable column. The protein complexes were eluted by Ni-NTA elution buffer (Ni-NTA wash buffer containing $300 \mathrm{mM}$ imidazole). The eluates were diluted 1:6 with a dilution buffer (Ni-NTA elution buffer without imidazole and $0.5 \mathrm{mM} \beta-\mathrm{ME}$ ) and bound to FLAG resin (Sigma) pre-equilibrated with dilution buffer in flow with a total contact time of $\sim 90$ minutes. Protein bound FLAG-resin was washed 3-times with FLAG wash buffer (50 mM Tris-HCl pH 7.5, $0.5 \mathrm{mM} \beta$ - 
ME, $150 \mathrm{mM} \mathrm{NaCl}, 10 \%$ glycerol, $1 \mathrm{mM} \mathrm{PMSF}$ ) and 2 times with the same buffer with $100 \mathrm{mM} \mathrm{NaCl}$ before being eluted with a FLAG elution buffer (FLAG wash buffer with $100 \mathrm{mM} \mathrm{NaCl}$ and $150 \mathrm{ng} / \mu \mathrm{l}$ $3 x$ FLAG peptide [Sigma]). Complexes were sub-aliquoted, snap frozen and stored at $-80{ }^{\circ} \mathrm{C}$ for later use.

Drosophila Topoisomerase I. To prepare N-terminally truncated Drosophila topoisomerase I (catalytic subunit) with 6xHis tag on its C-terminus, the ND423 plasmid (a kind gift from James T. Kadonaga, University of California, San Diego, USA), was transformed in BL21 (DE3) pLysS cells and protein was purified by nickel affinity chromatography ${ }^{82}$. The cell pellet from 1 liter culture was resuspended and sonicated in lysis buffer (50 mM Tris-HCl pH 7.5, $1 \mathrm{mM}$ PMSF, $500 \mathrm{mM} \mathrm{NaCl}, 10 \%$ glycerol, 2 $\mathrm{mM} \beta-\mathrm{ME}, 10 \mu \mathrm{g} / \mathrm{ml}$ leupeptin, $20 \mathrm{mM}$ imidazole) and supplemented with 1:400 protease inhibitor cocktail (Sigma). Soluble extract was obtained by centrifugation at $48,000 \mathrm{~g}$ for 30 minutes and was incubated with pre-equilibrated Ni-NTA resin for 2 hours at $4{ }^{\circ} \mathrm{C}$. Next, resin was washed 4 times with Ni-NTA wash buffer (50 mM Tris-HCl pH 7.5, 1 mM PMSF, $500 \mathrm{mM} \mathrm{NaCl}, 10 \%$ glycerol, $2 \mathrm{mM} \beta$ ME, $20 \mathrm{mM}$ imidazole). Before elution the resin was washed once with the same Ni-NTA wash buffer as above but with $100 \mathrm{mM} \mathrm{NaCl}$. Protein was eluted with elution buffer (50 mM Tris- $\mathrm{HCl} \mathrm{pH} 7.5,1$ mM PMSF, $100 \mathrm{mM} \mathrm{NaCl}, 10 \%$ glycerol, $0.5 \mathrm{mM} \beta$-ME, $300 \mathrm{mM}$ imidazole, $10 \mu \mathrm{g} / \mathrm{ml}$ leupeptin). Peak fractions were pooled and diluted 1:5 in dilution buffer (50 mM Tris-HCl pH 7.5, $0.5 \mathrm{mM} \beta-\mathrm{ME}$, $100 \mathrm{mM} \mathrm{NaCl}, 10 \%$ glycerol, $1 \mathrm{mM}$ PMSF, $10 \mu \mathrm{g} / \mathrm{ml}$ leupeptin) and the sample was loaded onto preequilibrated HiTrap S and HiTrap Heparin columns connected in tandem (GE Healthcare), and washed with $20 \mathrm{ml}$ of dilution buffer. The same buffer with a salt gradient up to $1 \mathrm{M} \mathrm{NaCl}$ was used to elute the protein from the HiTrap Heparin column after the HiTrap S column was disconnected. Peak fractions were pooled and dialyzed in dilution buffer for 2 hours. Protein was aliquoted, snap-frozen and stored at $-80^{\circ} \mathrm{C}$.

Yeast Rad51 (yRad51). The Rad51 sequence from S. cerevisiae was codon-optimized for bacterial expression and was purchased from GenScript. It was cloned into pMALT-P (a kind gift from the Kowalczykowski laboratory, UC Davis, USA) with BamHI and PstI restrictions sites. The construct codes for Rad51 protein with a N-terminal MBP-tag separated from Rad51 by a PreScission protease site. The plasmid was transformed into BL21 (DE3) pLysS cells, $0.2 \%$ glucose was used to supplement the culture medium. The cell pellet from 2 liters was resuspended and sonicated in Buffer A (50 mM Tris-HCl pH 7.5, $1 \mathrm{mM}$ PMSF, $500 \mathrm{mM} \mathrm{NaCl}, 1 \mathrm{mM}$ DTT, 10\% glycerol), supplemented with 1:500 protease inhibitor cocktail (Sigma). Soluble extract was obtained by centrifugation, and was incubated with amylose resin (New England Biolabs) at $4{ }^{\circ} \mathrm{C}$ for 1 hour in Buffer A containing 0.01\% NP40. Extensive washes were carried out with Buffer A with $1 \mathrm{M} \mathrm{NaCl}$, and subsequently with Buffer A containing 300 $\mathrm{mM} \mathrm{NaCl}$ without PMSF. MBP-Rad51 was eluted with $10 \mathrm{mM}$ maltose in Buffer A and $300 \mathrm{mM} \mathrm{NaCl}$.

611 Peak fractions were pooled, incubated with PreScission Protease for 1 hour at $4{ }^{\circ} \mathrm{C}(1: 7$; w/w $)$, and 
612 further diluted with $20 \mathrm{mM}$ Tris- $\mathrm{HCl} \mathrm{pH} 7.5$ to reduce $\mathrm{NaCl}$ concentration to $150 \mathrm{mM} \mathrm{NaCl}$ (final).

613 The sample was loaded onto pre-equilibrated HiTrap Q HP column (GE Healthcare). Buffer R (20 mM

614 Tris-HCl pH 7.5, 1 mM EDTA, $0.5 \mathrm{mM}$ DTT, $10 \%$ glycerol) with $150 \mathrm{mM} \mathrm{NaCl}$ was used to wash the

615 column. The same buffer $\mathrm{R}$ with a salt gradient up to $700 \mathrm{mM} \mathrm{NaCl}$ was used to elute the protein. Next,

616 peak fractions were pooled and dialyzed over-night in Buffer $\mathrm{R}$ with $100 \mathrm{mM} \mathrm{NaCl}$ and without EDTA.

617 Protein was aliquoted, snap-frozen and stored at $-80^{\circ} \mathrm{C}$.

618 Human RAD51. The RAD51 sequence was cloned from pTXB3-RAD51 construct $^{57}$ into pMALT-P 619 vector BamHI and PstI restriction sites, yielding N-terminal MBP tag, PreScission protease site and 620 RAD51. The mutants were created by site directed mutagenesis using QuikChange II site-directed mutagenesis kit following manufacturer's protocol (Agilent). The oligonucleotides used for mutagenesis are listed in supplementary Table S1. The RAD51 protein variants were expressed in BL21 (DE3) pLysS cells. Each culture was supplemented with $0.2 \%$ glucose, induced with $0.5 \mathrm{mM}$ IPTG and grown overnight at $18{ }^{\circ} \mathrm{C}$. The cells were then pelleted at $2,500 \mathrm{~g}$ for 15 minutes at $4{ }^{\circ} \mathrm{C}$, washed once with STE buffer (10 mM Tris- $\mathrm{HCl} \mathrm{pH} 8,500 \mathrm{mM} \mathrm{NaCl}, 1 \mathrm{mM}$ EDTA), snap-frozen and kept in $-80{ }^{\circ} \mathrm{C}$ until use. The pellets were then resuspended in lysis buffer $(50 \mathrm{mM}$ Tris- $\mathrm{HCl} \mathrm{pH}$ 7.5, $1 \mathrm{mM}$ PMSF, $1 \mathrm{mM}$ DTT, 10\% glycerol, $500 \mathrm{mM} \mathrm{NaCl}, 1: 500$ protease inhibitor cocktail [Sigma]), sonicated and lysate was clarified by centrifugation at $48,000 \mathrm{~g}$ for 30 minutes. Next, the lysate was incubated with amylose resin for 1 hour batch-wise at $4{ }^{\circ} \mathrm{C}$, washed first with wash buffer I (50 mM Tris- $\mathrm{HCl} \mathrm{pH} 7.5,1 \mathrm{mM}$ DTT, $10 \%$ glycerol, $1 \mathrm{M} \mathrm{NaCl})$ and then with wash buffer II (50 mM Tris-HCl pH 7.5, $1 \mathrm{mM}$ DTT, $10 \%$ glycerol, $300 \mathrm{mM} \mathrm{NaCl}$ ) followed by elution with wash buffer II containing $10 \mathrm{mM}$ maltose. To cleave off the MBP tag, PreScission Protease was added to the eluate and incubated overnight at $4{ }^{\circ} \mathrm{C}$ $(1: 5, \mathrm{w} / \mathrm{w})$. Cleaved RAD51 eluate was diluted with $50 \mathrm{mM}$ Tris- $\mathrm{HCl} \mathrm{pH} 7.5$ to lower the $\mathrm{NaCl}$ concentration to $150 \mathrm{mM}$. The eluate was then applied to a Hitrap Q column (GE Healthcare). The column was washed sequentially with wash buffer III (20 mM Tris-HCl pH 7.5, 1 mM EDTA, 0.5 mM DTT, $10 \%$ glycerol, $150 \mathrm{mM} \mathrm{NaCl}$ ) and eluted with wash buffer III with $300 \mathrm{mM} \mathrm{NaCl}$. The fractions containing RAD51 were pooled and dialyzed in $20 \mathrm{mM}$ Tris-HCl pH 7.5, $1 \mathrm{mM} \mathrm{DTT}, 20 \%$ glycerol and $100 \mathrm{mM} \mathrm{NaCl}$ overnight. The dialyzed protein was aliquoted, snap-frozen and stored at $-80{ }^{\circ} \mathrm{C}$. Wild type RAD51 was prepared from 4 liters of culture and all other variants were prepared from 1 liter cultures following the same purification procedure.

641 Human RPA. Recombinant human RPA was expressed from p11d-tRPA construct (a kind gift from 642 M. Wold, University of Iowa) in BL21 (DE3) pLysS cells. Bacterial culture was grown at $37^{\circ} \mathrm{C}(200$ 643 RPM) until O.D. $600=0.6$, induced with $0.4 \mathrm{mM} \mathrm{IPTG,} \mathrm{and} \mathrm{shaken} \mathrm{at} 18{ }^{\circ} \mathrm{C}(200 \mathrm{RPM})$ overnight. 644 Bacterial pellet was obtained by centrifugation, washed once with SD Buffer (10 mM Tris pH 8.0, 150 $\mathrm{mM} \mathrm{NaCl}, 1 \mathrm{mM}$ EDTA), snap-frozen and stored at $-80^{\circ} \mathrm{C}$. Cell lysis, followed by purification using 646 ÄKTA pure (GE Healthcare) using HiTrap Blue HP, HiTrap desalting and HiTrap Q chromatography columns (all GE Healthcare) ${ }^{83}$. 
648 Human mitochondrial single-stranded DNA binding protein (SSB). Recombinant mitochondrial 649 SSB was expressed and purified from E. coli BL21 cells ${ }^{84}$.

650 Human DNA2 and WRN. Recombinant DNA2 was expressed in $S f 9$ insect cells and purified by af651 finity chromatography by utilizing the $\mathrm{N}$-terminal $6 x$ His and the C-terminal FLAG affinity tags ${ }^{83}$. WRN 652 was purified by exploiting the maltose-binding protein (MBP) tag at the N-terminus and 10xHis tag at 653 the C-terminus. The MBP tag was cleaved off with PreScission Protease during purification. Detailed 654 procedures were described ${ }^{83,84}$.

655 Human MRN, MR, MRE11, phosphorylated CtIP and EXO1. Recombinant MRN (MRE11656 RAD50-NBS1) and MR (MRE11-RAD50) were purified as a complex from Sf9 insect cells. Individual baculoviruses coding for MRE11-6xHis, RAD50co-FLAG and NBS1co were prepared by standard laboratory procedures according to manufacturer's instructions (Bac-to-Bac, Life Technologies). Detailed procedures describing purification strategies have been described ${ }^{83}$. Briefly, the purification involved affinity chromatography using NiNTA agarose (Qiagen) and anti-FLAG affinity resin (Sigma). Recombinant MRE11 alone was prepared using pFB-MBP-MRE11-His vector, using amylose resin, PreScission Protease to remove the MBP tag, followed by affinity chromatography with NiNTA agarose $^{85}$. Phosphorylated CtIP was purified from $S f 9$ cells using amylose and NiNTA resins ${ }^{3}$. The recombinant human EXO1 gene was expressed from pFB-EXO1-FLAG in Sf9 insect cells by using the Bacto-Bac expression system (Invitrogen), according to manufacturer's recommendations. Protein purification was performed with anti-FLAG (Sigma) affinity chromatography followed by HiTrap SP HP ion exchange chromatography (GE Healthcare) utilizing ÄKTA pure (GE Healthcare) ${ }^{86}$.

Yeast MRX, Mre11, phosphorylated Sae2 and Exo1. The proteins were prepared from Sf9 insect cells and purified using affinity and ion exchange chromatography ${ }^{87,88,89}$. Exo1 was prepared according to an established procedure ${ }^{67}$.

\section{Preparation of oligonucleotide-based DNA substrates.}

672 Oligonucleotides were either 5'-end-labeled with $\left[\gamma^{3}{ }^{32} \mathrm{P}\right]$-ATP (Perkin Elmer) and T4 polynucleotide 673 kinase (NEB), or 3'-end-labeled with $\left[\alpha{ }^{32} \mathrm{P}\right]$-dCTP (Perkin Elmer) and terminal transferase (NEB) en674 zymes, respectively. The labeled DNA was then purified on a Micro Bio-Spin P-30 Tris chromatog675 raphy columns (Bio-Rad) ${ }^{90}$. Sequences for all oligonucleotides used to obtain the DNA substrates are 676 listed in supplementary Table S1.

677 Branch migration substrate was prepared as described previously ${ }^{91}$. Briefly, 5'- or 3'-end-labeled $2 \mu \mathrm{M}$ $678 \mathrm{XO1}$ was mixed with $2.4 \mu \mathrm{M}$ XO2 (1:1.2 ratio) in annealing buffer (10 mM Tris- $\mathrm{HCl} \mathrm{pH} 8,50 \mathrm{mM}$ $679 \mathrm{NaCl}, 10 \mathrm{mM} \mathrm{MgCl}_{2}$ ). In parallel, $2 \mu \mathrm{M}$ each (1:1 ratio) of XO1c.MM2 and XO2c.MM oligonucleotides 680 were similarly combined. The respective mixes were heated for 3 minutes at $95{ }^{\circ} \mathrm{C}$ and slowly cooled 681 down to room temperature overnight. The two respective samples were then combined and annealed 
together $\left(37^{\circ} \mathrm{C}\right.$ for 30 minutes), followed by gradual cooling down to room temperature ( 2 hours).

683 Substrate was then stored at $-20{ }^{\circ} \mathrm{C}$ until further use.

684 Fork reversal substrates were prepared as described earlier ${ }^{42}$. Briefly, to create a fork with a leading 685 strand gap, 3'- or 5'-labeled nascent \#DC-6 (100 nM final) was annealed with unlabeled parental \#DC6862 (120 nM final) in annealing buffer (as above) by heating ( 3 minutes at $95{ }^{\circ} \mathrm{C}$ ) and gradually cooled 687 down to room temperature overnight. Similarly, the complementary half comprising of unlabeled pa688 rental \#DC-1 (180 nM final) and unlabeled nascent \#DC-4 (180 nM final) were separately annealed. 689 These two corresponding halves (\#DC-6 + \#DC-2 and \#DC-1 + \#DC-4) were then combined and an690 nealed at $37^{\circ} \mathrm{C}$ for 45 minutes and then cooled down to room temperature during 2 hours, and stored 691 at $-20^{\circ} \mathrm{C}$ until further use. To create a fork with a lagging strand gap, 3'- or 5'-labeled nascent \#DC-3 692 (100 nM final) was annealed with unlabeled parental \#DC-1 (120 nM final) and the corresponding half 693 containing unlabeled parental \#DC-2 (150 nM final) was annealed with unlabeled nascent \#DC-5 (150 694 nM final) oligos. These two halves (\#DC-3 + \#DC-1 and \#DC-2 + \#DC-5) were then combined and 695 annealed as above.

696 To prepare the 5'-labeled 70 bp-long dsDNA substrate, which was quadruple blocked with streptavidin, 697 the oligonucleotides PC210 and PC211 were used ${ }^{89}$. To prepare 5'-labeled 50 bp-long dsDNA, oligo698 nucleotides X12-3 and X12-4C were annealed. To prepare 5'-overhang substrate, X12-3 and X12-4SC 699 were annealed, creating a structure with 19 nt-long 5'-overhang and 31 base pairs of dsDNA. To prepare 700 3'-overhang substrate, X12-3SC + X12-4NC were annealed, creating a structure with 19 nt-long 3'overhang and 31 base pairs of dsDNA, as described ${ }^{92}$.

\section{Topoisomerase-coupled annealing assays}

704 The bubbled DNA annealing assay was performed as described ${ }^{43}$ with the following modifications. pBluescript II KS (+) plasmid (a kind gift from Marcus Thelen, IRB, Bellinzona, Switzerland) was used as a substrate. $100 \mathrm{ng}$ supercoiled DNA was mixed with $1 \mu \mathrm{g}$ RPA in TE pH 8.0 in $10 \mu$ l volume, and incubated for 45 minutes at $37^{\circ} \mathrm{C}$. Next, $16.5 \mathrm{nM}$ (final) of catalytic domain of Drosophila topoisomerase I was added to the reaction mixture and incubated for additional 10 minutes at $37{ }^{\circ} \mathrm{C}$. Next, annealing buffer (20 mM Tris- $\mathrm{HCl} \mathrm{pH}$ 7.5, $5 \mathrm{mM} \mathrm{MgCl}_{2}, 1 \mathrm{mM}$ DTT, $0.2 \mathrm{mg} / \mathrm{ml} \mathrm{BSA}, 100 \mathrm{mM} \mathrm{NaCl}$ ), $2.5 \mathrm{mM}$ ATP (final) and corresponding amounts of proteins (as indicated in figures) or protein storage buffer were added. The final volume was adjusted to $20 \mu \mathrm{l}$ with water and the reactions were incubated for 30 minutes at $37^{\circ} \mathrm{C}$. The reactions were terminated by adding $2.5 \mu \mathrm{l}$ of $5 \mathrm{M} \mathrm{NaCl}$ at room temperature for 2 minutes, followed by $6.5 \mu$ of $2 \%$ stop buffer $(100 \mathrm{mM}$ Tris- $\mathrm{HCl} \mathrm{pH} 7.5,150 \mathrm{mM}$ EDTA, $2 \%$ SDS [w/v], 30\% glycerol, $0.1 \%$ bromophenol blue) and $1 \mu$ Proteinase $\mathrm{K}$ ( $20 \mathrm{mg} / \mathrm{ml}$, Roche), and incubated 10 minutes at $37^{\circ} \mathrm{C}$. The mixture was resolved by $1 \%$ agarose gel electrophoresis in $1 \mathrm{x}$ TAE buffer, and DNA was visualized by post-staining with GelRed (Biotium) according to manufacturer's 
717 instructions. The gels were then imaged (InGenius3, GeneSys) and quantitated as the fraction of near

718 or fully relaxed DNA using Image J. Graphs were generated by GraphPad Prism software.

\section{Fork reversal and branch migration assays}

720 The assays were carried out in a reaction buffer containing $20 \mathrm{mM}$ Tris- $\mathrm{HCl} \mathrm{pH} 7.5,5 \mathrm{mM} \mathrm{MgCl} 2,1$ $\mathrm{mM}$ DTT, $0.1 \mathrm{mg} / \mathrm{ml} \mathrm{BSA,} \mathrm{10 \%} \mathrm{glycerol,} 2.5 \mathrm{mM}$ ATP (unless indicated otherwise), and $1 \mathrm{nM}$ (fork reversal) or $0.5 \mathrm{nM}$ (branch migration) DNA substrate, with $150 \mathrm{mM} \mathrm{NaCl}$ (unless indicated otherwise). Master-mixes were prepared on ice and where indicated, RPA $(3 \mathrm{nM})$ was added to the master-mix for 15 minutes on ice. $13 \mu \mathrm{l}$ reaction mixture was then dispersed to individual tubes and supplemented with other recombinant proteins (as indicated) and final volume was adjusted to $15 \mu 1$ with protein storage buffer. The reactions were continued for additional 30 minutes at $37^{\circ} \mathrm{C}$ and terminated by the addition of $5 \mu \mathrm{l}$ stop buffer (100 mM Tris-HCl pH 7.5, $150 \mathrm{mM}$ EDTA, 0.2\% SDS [w/v], 30\% glycerol, 0.1\% bromophenol blue) and $1 \mu \mathrm{l}$ Proteinase $\mathrm{K}\left(20 \mathrm{mg} / \mathrm{ml}\right.$, Roche) and incubated for 10 minutes at $37{ }^{\circ} \mathrm{C}$. Samples were loaded onto 8\% polyacrylamide (19:1 acrylamide:bisacrylamide) gels in 1x Tris-borateEDTA (TBE) (BIO-RAD Mini-PROTEAN system, $1 \mathrm{~mm}$ thick) and separated for 60 minutes at $80 \mathrm{~V}$ at room temperature. The gels were dried using a BIO-RAD gel drier on 17 CHR paper (Whatman), and were exposed to storage phosphor screens and scanned using Typhoon FLA 9500 (GE Healthcare) phosphor imager. The gels were quantitated with ImageJ. Graphs were generated by GraphPad Prism software.

\section{Single-stranded DNA annealing assay}

DNA annealing reactions were carried out at $37^{\circ} \mathrm{C}$ for the times indicated using complementary oligonucleotides X12-3 and X12-4C (please see supplementary Table S1 for sequences), $1 \mathrm{nM}$ each. The X12-3 oligonucleotide was labeled at the 5'-end. Control reactions were supplemented with protein storage buffer. Reaction master mixes were prepared separately with the respective ssDNA in a buffer containing $25 \mathrm{mM}$ Tris-acetate $\mathrm{pH}$ 7.5, $5 \mathrm{mM}$ magnesium acetate, $1 \mathrm{mM}$ DTT, $1 \mathrm{mM}$ ATP and supplemented with $4 \mathrm{nM}$ RPA or SSB where indicated. The two respective master mixes were then incubated for 5 minutes at $37{ }^{\circ} \mathrm{C}$ to allow RPA or SSB binding. The two respective mixes containing complementary ssDNA were then combined. Motor proteins and cofactors (when indicated) were added immediately and reaction volume was adjusted with water. The reactions were then incubated at $37^{\circ} \mathrm{C} ; 15 \mu \mathrm{l}$ reaction mixture was withdrawn at the indicated time points into tubes containing $5 \mu 1$ stop buffer (100 $\mathrm{mM}$ Tris-HCl pH 7.5, $150 \mathrm{mM}$ EDTA, 0.2\% SDS [w/v], 30\% glycerol, 0.1\% bromophenol blue) and 1 
onto 8\% polyacrylamide (19:1 acrylamide:bisacrylamide) gels in 1x TBE (BIO-RAD Mini-PROTEAN system, $1 \mathrm{~mm}$ thick), and processed as described above.

\section{ATPase assays}

ATPase assays were performed in a buffer containing $20 \mathrm{mM}$ Tris- $\mathrm{HCl} \mathrm{pH}$ 7.5, $5 \mathrm{mM} \mathrm{MgCl} 2,1 \mathrm{mM}$ DTT, $0.1 \mathrm{mg} / \mathrm{ml} \mathrm{BSA,} 10 \%$ glycerol, $100 \mathrm{mM} \mathrm{NaCl}$ (unless otherwise indicated in the figures), $100 \mathrm{nM}$ ATP, $1 \mathrm{nM}$ of $\left[\gamma^{-32} \mathrm{P}\right]$ ATP (Perkin Elmer). 2961 bp long supercoiled pBluescript II KS (+) (7 nM, in molecules) or $5 \mathrm{nM}$ unlabeled fork (\#DC-1 + \#DC-2) or Holliday junction structures $([\mathrm{XO} 1+\mathrm{XO} 2]+$ $[\mathrm{XO} 1 \mathrm{c} . \mathrm{MM} 2+\mathrm{XO} 2 \mathrm{c} . \mathrm{MM}])$ were used as a substrate. Recombinant proteins were added on ice and the samples were incubated at $37{ }^{\circ} \mathrm{C}$ for 60 minutes. Reactions were stopped with $2 \mu 1$ of $0.5 \mathrm{M}$ EDTA and separated using TLC plates (Merk) and $0.3 \mathrm{M} \mathrm{LiCl}$ and $0.3 \mathrm{M}$ formic acid as a mobile phase. Dried plates were exposed to storage phosphor screens (GE Healthcare) and scanned by a Typhoon FLA 9500 phosphorimager (GE Healthcare). Signals were quantified using ImageJ software. Spontaneous ATP hydrolysis signal (Pi) from no protein lanes were removed as a background and the fraction of ATP hydrolysis was obtained as a normalized value. Graphs were generated by GraphPad Prism software.

\section{Electrophoretic mobility shift assays}

The electrophoretic mobility shift assay (EMSA) to characterize the binding of BCDX2 complex to 70mer ssDNA (PC210) or dsDNA (PC210 annealed with PC211), $1 \mathrm{nM}$ final; was carried out in $15 \mu \mathrm{l}$ volume in a binding buffer containing $20 \mathrm{mM}$ Tris-acetate $\mathrm{pH}$ 7.5, $1 \mathrm{mM}$ DTT, $1 \mathrm{mM}$ magnesium acetate, $0.1 \mathrm{mg} / \mathrm{mL}$ BSA (NEB) and $1 \mathrm{mM} \mathrm{ATP.} \mathrm{PC210} \mathrm{was} \mathrm{labeled} \mathrm{at} \mathrm{5'} \mathrm{end.} \mathrm{Reactions} \mathrm{were} \mathrm{assem-}$ bled on ice and supplemented with increasing concentrations of BCDX2, and incubated for 30 minutes at $37{ }^{\circ} \mathrm{C}$. The reactions were mixed with $5 \mu$ l loading buffer (50\% glycerol, $0.1 \%$ bromophenol blue) and loaded on $8 \%$ polyacrylamide (19:1 acrylamide:bisacrylamide) gels in 1x TBE (BIO-RAD MiniPROTEAN system, $1 \mathrm{~mm}$ thick), and separated for 150 minutes at $80 \mathrm{~V}$ at $4{ }^{\circ} \mathrm{C}$. The gels were dried using a BIO-RAD gel drier on 17 CHR paper (Whatman), exposed to storage phosphor screens and scanned using Typhoon FLA 9500 (GE Healthcare) phosphor imager.

\section{Protein-protein interaction assays}

To study the interaction between SMARCAL1 wild type and corresponding SMARCAL1 F $\rightarrow$ A variants with RAD51 or between ZRANB3 WT, ZRANB3 F $\rightarrow$ A variants with RAD51, bacterial soluble extract containing MBP-RAD51 was incubated with amylose resin $(50 \mu 1, \mathrm{NEB})$. The resin was washed with wash buffer I ( $25 \mathrm{mM}$ Tris-HCl pH 7.5, $0.5 \mathrm{mM}$ DTT, $3 \mathrm{mM}$ EDTA, $100 \mathrm{mM} \mathrm{NaCl}, 0.2 \mu \mathrm{g} / \mu 1$ 
783

784

785

786

787

788

789

790

791

792

793

794

795

796

797

798

799

800

801

802

803

804

805

806

807

808

809

810

811

812

813

814

815

816

817

BSA) and incubated with recombinant purified FLAG-SMARCAL1, FLAG-ZRANB3 or the FLAGBCDX2 complex (all $1 \mu \mathrm{g}$ ) in $150 \mu \mathrm{lP}$ buffer ( $25 \mathrm{mM}$ Tris- $\mathrm{HCl} \mathrm{pH}$ 7.5, 0.5 mM DTT, $3 \mathrm{mM}$ EDTA, $100 \mathrm{mM} \mathrm{NaCl}, 0.2 \mu \mathrm{g} / \mu \mathrm{BSA}, 10 \%$ Glycerol) for 1 hour at $4{ }^{\circ} \mathrm{C}$. The resin with bound proteins was washed 5 times with $1 \mathrm{ml}$ wash buffer III ( $25 \mathrm{mM}$ Tris-HCl pH 7.5, 1 mM DTT, 3 mM EDTA, 100 $\mathrm{mM} \mathrm{NaCl}, 0.05 \%$ Triton X-100), and eluted with wash buffer III (70 $\mu$ l) containing $30 \mathrm{mM}$ maltose and Avidin $(0.11 \mu \mathrm{g} / \mu \mathrm{l})$ as a stabilizer. Samples were analyzed by Western blotting using anti-MBP primary antibody (MBL, M091-3, 1:1000) against MBP-RAD51 and anti-FLAG primary antibody (Sigma, F3165, 1:1000) against SMARCAL1, ZRANB3 or against RAD51B of the BCDX2 complex, respectively, by standard procedures.

To study interaction between RAD51 and ZRANB3 variants, FLAG-tagged ZRANB3 variants were expressed in $S f 9$ cells, cells were lysed and soluble extract containing the FLAG-ZRANB3 proteins was bound to M2 anti-FLAG affinity resin (50 $\mu$ l, Sigma). The resin was washed 3-times with $1 \mathrm{ml}$ wash buffer I ( $25 \mathrm{mM}$ Tris-HCl pH 7.5, $0.5 \mathrm{mM}$ DTT, $3 \mathrm{mM}$ EDTA, $100 \mathrm{mM} \mathrm{NaCl}, 0.2 \mu \mathrm{g} / \mu 1 \mathrm{BSA}$ ) and incubated for 1 hour at $4{ }^{\circ} \mathrm{C}$ with recombinant purified RAD51 $(1 \mu \mathrm{g})$ in $150 \mu \mathrm{IP}$ buffer $(25 \mathrm{mM}$ Tris$\mathrm{HCl}$ pH 7.5, $0.5 \mathrm{mM}$ DTT, $3 \mathrm{mM}$ EDTA, $100 \mathrm{mM} \mathrm{NaCl}, 0.2 \mu \mathrm{g} / \mu \mathrm{l} \mathrm{BSA})$. The resin with bound proteins was washed 5-times with $1 \mathrm{ml}$ wash buffer II (25 mM Tris-HCl pH 7.5, $0.5 \mathrm{mM}$ DTT, 3 mM EDTA, $100 \mathrm{mM} \mathrm{NaCl}, 0.1 \% \mathrm{NP} 40,0.2 \mu \mathrm{g} / \mu \mathrm{lBSA})$, and proteins were eluted with wash buffer II (70 $\mu \mathrm{l})$ containing $150 \mathrm{ng} / \mu 1$ 3xFLAG peptide (GLPBIO) and Avidin ( $0.11 \mu \mathrm{g} / \mu 1$ [Sigma]) as a stabilizer. Samples were analyzed by Western blotting using anti-RAD51 primary antibody (Abcam-133534, 1:1000) or by Ponceau staining to show ZRANB3, using standard laboratory procedures.

To study the interaction between ZRANB3 and the BCDX2 complex, or between SMARCAL1 variants and the BCDX2 complex, $1 \mu \mathrm{g}(1 \mu \mathrm{l})$ anti-His primary antibody (MBL-D2913) was mixed with $15 \mu 1$ Dynabeads Protein G (Invitrogen) slurry in a solution containing $150 \mu 1 \mathrm{X}$ PBS containing $0.05 \%$ Tween 20 (PBS-T). The mixture was incubated for 45 minutes at room temperature with gentle mixing. The cocktail was washed 3 times with $150 \mu$ PBS-T and was further resuspended in $60 \mu 1$ IP buffer (25 $\mathrm{mM}$ Tris-HCl pH 7.5, $0.5 \mathrm{mM}$ DTT, $3 \mathrm{mM}$ EDTA, $100 \mathrm{mM} \mathrm{NaCl}, 0.2 \mu \mathrm{g} / \mu \mathrm{lBSA}$ ), which was then supplemented with $1 \mu \mathrm{g}$ recombinant purified BCDX2 complex and incubated for 1 hour at $4{ }^{\circ} \mathrm{C}$ with gentle mixing. The beads were washed 3-times with $150 \mu 1$ wash buffer $(50 \mathrm{mM}$ Tris- $\mathrm{HCl} \mathrm{pH}$ 7.5, 1 mM DTT, 3 mM EDTA, $100 \mathrm{mM} \mathrm{NaCl}, 0.05 \%$ Triton X-100) and again resuspended in IP buffer. Purified recombinant SMARCAL1 or ZRANB3 $(1 \mu \mathrm{g})$ was added and incubated for 1 hour at $4{ }^{\circ} \mathrm{C}$ with gentle mixing, and washed 4-times with wash buffer (50 mM Tris- $\mathrm{HCl} \mathrm{pH}$ 7.5, $100 \mathrm{mM} \mathrm{NaCl}, 0.05 \%$ Triton X-100). Proteins were eluted by heating the beads for 3 minutes at $95{ }^{\circ} \mathrm{C}$ in $60 \mu \mathrm{LDS}$ buffer (50 mM Tris- $\mathrm{HCl}$ pH 6.8, $1.6 \%$ SDS, $10 \%$ Glycerol, 10\% DTT, $0.01 \%$ Bromophenol Blue) and transferred to a new tube containing Avidin as a stabilizer $(0.11 \mu \mathrm{g} / \mu \mathrm{l})$. Samples were resolved by polyacrylamide gel electrophoresis and protein bands were visualized either by silver staining or by 
818 Western blotting using anti-FLAG to detect SMARCAL1 and ZRANB3, and by anti-His primary anti-

819 bodies to detect RAD51C of the BCDX2 complex by standard procedures.

820

821 Antibodies. The antibodies used for Western blotting, immunoprecipitation and DNA fiber assay were 822 used as follows: Mouse anti-RAD51B (Santa Cruz sc-377192; 1:1,000 dilution for WB), Mouse anti823 XRCC2 (Santa Cruz sc-365854; 1:1,000 dilution for WB), Mouse anti-XRCC3 ( Santa Cruz sc-271714; 824 1:1,000 dilution for WB), Rabbit anti-RAD51C (Abcam ab95069; 1:1,000 dilution for WB), Rabbit 825 anti-RAD51D (Abcam ab202063; 1:1,000 dilution for WB), Rat anti-BrdU (Abcam ab6326; 1:100 di826 lution for DNA fiber assay), Mouse anti-BrdU (Becton Dickinson BD347580; 1:100 dilution for DNA 827 fiber assay), Mouse anti-SMARCAL1 (Santa Cruz sc-376377; 1:1,000 dilution for WB), Mouse anti828 BRCA1 (Santa Cruz sc-6954; 1:100 dilution for WB), Rat anti-TUBULIN (Abcam ab-6160; 1:50,000 829 dilution for WB), Goat anti-mouse Alexa Fluor 488 (Thermo Fisher A-11029; 1:300 dilution for DNA 830 fiber assay), Goat anti-rabbit Alexa Fluor 594 (Thermo Fisher A-11008; 1:300 dilution for DNA fiber 831 assay), Mouse anti-his (MBL D291-3; $1 \mu \mathrm{g}$ for pulldown assay), Mouse anti-FLAG (Sigma F3165; 832 1:2,000 dilution for WB), Mouse anti-MBP (MBL M091-3; 1:1,000 dilution for WB), Rabbit anti833 RAD51 (Abcam ab133534; 1:1,000 dilution for WB).

834

\section{Nuclease protection assays}

836 Endonuclease assays with MRN-pCtIP were performed in a $15 \mu 1$ volume in a nuclease buffer ( $25 \mathrm{mM}$ 837 Tris- $\mathrm{HCl} \mathrm{pH}$ 7.5, $1 \mathrm{mM}$ manganese acetate, $5 \mathrm{mM}$ magnesium acetate, $1 \mathrm{mM}$ DTT, $1 \mathrm{mM} \mathrm{ATP}, 0.25$ $838 \mathrm{mg} / \mathrm{mL}$ BSA, $1 \mathrm{mM}$ phosphoenolpyruvate, $80 \mathrm{U} / \mathrm{ml}$ pyruvate kinase [Sigma]) with $1 \mathrm{nM}$ biotinylated 839 DNA substrate (in molecules, 70 bp-long, 5'-end-labeled PC210 and PC211) and incubated with strep840 tavidin (15 nM, Sigma) for 5 minutes at room temperature to block the DNA ends. Before the addition 841 of nucleases, increasing amounts of yeast and human RAD51 were added to the reactions and preincu842 bated for 10 minutes at $37^{\circ} \mathrm{C}$. Recombinant MRN and pCtIP were subsequently added, and the reaction 843 was incubated for 2 hours at $37^{\circ} \mathrm{C}$. Endonuclease assays with yeast MRX-pSae2 were performed sim844 ilarly as MRN-pCtIP, however yeast and human RAD51 assembly (10 minutes incubation) and subse845 quent reactions were performed at $30^{\circ} \mathrm{C}$ for 30 minutes.

846 Exonuclease assays with human MR were performed in the nuclease buffer as above, but with $5 \mathrm{nM}$ 847 DNA substrate (in molecules, except where mentioned otherwise), which was 50 bp-long dsDNA (X128483 and X12-4C) or with a 3' (X12-3SC + X12-4NC) or 5' (X12-3 and X12-4SC) overhangs. Yeast and 849 human RAD51 were then preassembled for 10 minutes on DNA at $37{ }^{\circ} \mathrm{C}$ and the assays were subse850 quently incubated for 120 minutes at $37^{\circ} \mathrm{C}$ after adding the nucleases. RAD51 assembly and subsequent 851 nuclease assays with yeast MR were performed at $30^{\circ} \mathrm{C}$. 
852 For nuclease assays with MRE11, the reaction buffer contained $25 \mathrm{mM}$ Tris- $\mathrm{HCl} \mathrm{pH}$ 7.5, $3 \mathrm{mM}$ man853 ganese acetate, $5 \mathrm{mM}$ magnesium acetate, $1 \mathrm{mM} \mathrm{DTT}, 1 \mathrm{mM} \mathrm{ATP}, 0.25 \mathrm{mg} / \mathrm{ml} \mathrm{BSA}, 1 \mathrm{mM}$ phosphoe854 nolpyruvate and $80 \mathrm{U} / \mathrm{ml}$ pyruvate kinase (Sigma). $1 \mathrm{nM}$ 5'-end-labeled 50 bp-long dsDNA (in mole855 cules, X12-3 and X12-4C) was used as a substrate. Human or yeast RAD51/Rad51 assembly (10 856 minutes) and further reactions were carried out at $37^{\circ} \mathrm{C}$ for 120 minutes.

857 Nuclease assays with human EXO1 were performed with $1 \mathrm{nM}$ 5'-end-labeled 50 bp-long dsDNA sub858 strate (in molecules, X12-3 and X12-4C) in a buffer with $25 \mathrm{mM}$ Tris-HCl pH 7.5, $2 \mathrm{mM}$ magnesium 859 acetate, $1 \mathrm{mM}$ DTT, $1 \mathrm{mM}$ ATP, $0.1 \mathrm{mg} / \mathrm{ml} \mathrm{BSA}, 1 \mathrm{mM}$ phosphoenolpyruvate and $80 \mathrm{U} / \mathrm{ml}$ pyruvate 860 kinase (Sigma). Human or yeast RAD51/Rad51 was assembled on DNA for 10 minutes at $37{ }^{\circ} \mathrm{C}$ and 861 the reactions were further incubated at $37^{\circ} \mathrm{C}$ for 30 minutes. However, for assays with yeast Exo1, the 862 buffer contained $5 \mathrm{mM}$ magnesium acetate and the reactions were performed at $30^{\circ} \mathrm{C}$.

863 Endonuclease assays with NspI (NEB) were performed with $1 \mathrm{nM}$ (in molecules) 5'-end-labeled $50 \mathrm{bp}$ 864 long dsDNA (X12-3 and X12-4C) in CutSmart buffer (NEB) and supplemented with 2.5 mM ATP to 865 aid RAD51 binding to DNA. Substrates were preincubated with increasing amount of human or yeast 866 Rad51 for 10 minutes at $37^{\circ} \mathrm{C}$ followed by the addition of 1 unit of NspI (per $15 \mu \mathrm{l}$ ) and further incu867 bation for 30 minutes at $37^{\circ} \mathrm{C}$.

868 EXO-III mediated Holliday junction degradation assay ( $0.5 \mathrm{nM} 5$ '-end-labeled substrate, in molecules) was performed in branch migration assay buffer containing $100 \mathrm{mM} \mathrm{NaCl}$. However, in the assays comparing the DNA protection by human and yeast RAD51/Rad51, $1 \mathrm{nM}$ 5'-end-labeled 50 bp-long dsDNA substrate was used in branch migration assay buffer without additional salt. RAD51 assembly (10 minutes) and subsequent reactions ( 30 minutes) were performed at $37^{\circ} \mathrm{C}$.

All reactions were stopped with $0.5 \mu$ l EDTA $(0.5 \mathrm{M})$ and $1 \mu$ l proteinase $\mathrm{K}(20 \mathrm{mg} / \mathrm{ml}$, Roche), and incubated at $50{ }^{\circ} \mathrm{C}$ for 30 minutes. An equal volume of formamide dye $(95 \%[\mathrm{v} / \mathrm{v}]$ formamide, $20 \mathrm{mM}$ EDTA, $0.1 \%$ bromophenol blue) was added and the samples were heated at $95{ }^{\circ} \mathrm{C}$ for 4 minutes and separated on 15\% denaturing polyacrylamide gels (ratio acrylamide: bisacrylamide 19:1, Bio-Rad). The gels were fixed for 30 minutes at room temperature (40\% methanol, $10 \%$ acetic acid, $5 \%$ glycerol) and dried on a 3 MM CHR paper (Whatman). The dried gels were exposed to storage phosphor screens (GE Healthcare) and scanned by a Typhoon phosphor imager (FLA 9500, GE Healthcare). The gels were quantitated with ImageJ. Graphs were generated by GraphPad Prism software.

881 For DNA2-catalyzed assays, randomly labeled 2.2-kbp-long substrate was prepared by amplifying the human NBS1 gene by PCR from pFB-MBP-NBS1-his plasmid ${ }^{85}$ using Phusion high-fidelity DNA polymerase (New England Biolabs) and the NBS1_F and NBS1_R primers (see Table S1). $66 \mathrm{nM}[\alpha-$ $\left.{ }^{32} \mathrm{P}\right] \mathrm{dCTP}$ was added to the PCR reaction together with the standard dNTPs concentration $(200 \mu \mathrm{M}$ each). The PCR reaction product was purified using the QIAquick PCR purification kit (Qiagen) and 
886 Chroma Spin TE-200 columns (Clontech). Purified DNA was quantitated by comparing the radioactive 887 DNA fragment with known amounts of a cold PCR product on an agarose gel stained with GelRed 888 (Biotium). Nuclease assays with PCR-based DNA substrates ${ }^{86}$ were performed in a $15 \mu 1$ volume in a 889 reaction buffer containing $25 \mathrm{mM}$ Tris-acetate $\mathrm{pH}$ 7.5, $2 \mathrm{mM}$ magnesium acetate, $1 \mathrm{mM}$ ATP, $1 \mathrm{mM}$ 890 DTT, $0.1 \mathrm{mg} / \mathrm{ml} \mathrm{BSA,} 1 \mathrm{mM}$ phosphoenolpyruvate (PEP), $80 \mathrm{U} / \mathrm{ml}$ pyruvate kinase (Sigma), $50 \mathrm{mM}$ $891 \mathrm{NaCl}$, RPA (176 nM) and $1 \mathrm{nM}$ substrate (in molecules). Increasing amount of RAD51 (as indicated 892 in the figure) was preincubated with the substrates for 10 minutes at $37^{\circ} \mathrm{C}$ in the reaction buffer, which 893 was then supplemented with other recombinant proteins and the reaction was continued for 30 minutes 894 at $37{ }^{\circ} \mathrm{C}$. Reactions were stopped with $5 \mu 12 \%$ stop solution (150 mM EDTA, $2 \%$ sodium dodecyl 895 sulfate, $30 \%$ glycerol, $0.1 \%$ bromophenol blue) and $1 \mu \mathrm{l}$ of proteinase $\mathrm{K}(20 \mathrm{mg} / \mathrm{ml}$, Roche) and incu896 bated at $37^{\circ} \mathrm{C}$ for 10 minutes. Samples were resolved by $1 \%$ agarose gel electrophoresis. Gels were 897 dried on DE81 chromatography paper (Whatman), exposed to storage phosphor screens (GE 898 Healthcare) and scanned by a Typhoon 9500 phosphor imager (GE Healthcare). The gels were quanti899 tated with ImageJ. Graphs were generated by GraphPad Prism software.

900

\section{Cellular assays}

902 MCF10A cells were maintained in a 1:1 mixture of DMEM and Ham's F12 medium (Thermo Fisher Scientific), supplemented with 5\% horse serum (Thermo Fisher Scientific), $20 \mathrm{ng} / \mathrm{ml}$ human epidermal growth factor (Peprotech), $100 \mathrm{ng} / \mathrm{ml}$ cholera toxin, $10 \mu \mathrm{g} / \mathrm{ml}$ insulin and $0.5 \mu \mathrm{g} / \mathrm{ml}$ hydrocortisone (Sigma-Aldrich). The human embryonic kidney fibroblast cell line HEK293T was maintained in DMEM supplemented with 10\% Fetalgro bovine growth serum. Gateway LR recombination (Thermo Fisher Scientific) was used to recombine pDONR223-SMARCAL1(F446A) with the lentiviral expression vector pHAGE-C-FLAG-HA-DEST ${ }^{93}$. Recombinant lentiviruses were generated by cotransfecting helper packaging vectors together with lentiviral vectors into HEK293T cells using the TransIT-

910293 transfection reagent (Mirus Bio). Virus-containing supernatants were collected 48 hours after trans-

911 fection and utilized to infect MCF10A cells in the presence of $8 \mu \mathrm{g} / \mathrm{ml}$ polybrene. 48 hours after viral 912 addition, MCF10A cells were selected using $1 \mu \mathrm{g} / \mathrm{ml}$ puromycin for 3 days. To perform RNAi treat913 ments, MCF10A SMARCAL1 KO cells complemented with WT and F446A mutant SMARCAL1 were 914 transfected with control or BRCA1 siRNA (GE Dharmacon) using lipofectamine RNAiMAX (Thermo 915 Fisher Scientific) according to manufacturer's instructions and subjected to DNA fiber assays 3 days 916 after transfection. To analyze cell lysates by Western blotting, cells were collected by trypsinization 917 and lysed in SB lysis buffer (62.5 mM Tris- $\mathrm{HCl} \mathrm{pH}$ 6.8, 1.25\% SDS, $12 \%$ glycerol, $0.71 \mathrm{M}$ [5\%] $\beta$ 918 ME, $0.002 \%$ bromophenol blue). Whole cell extracts were sonicated and heated for 5 minutes at $95{ }^{\circ} \mathrm{C}$. 919 Following gel electrophoresis and transfer of cell extracts onto nitrocellulose, membranes were incu920 bated for 1 hour or overnight in blocking buffer ( $5 \%$ milk in TBS $+0.1 \%$ Tween20). Membranes were 
926

927

928

929

930

931

932

933

934

935

936

937

938

939

940

941

942

943

944

945

946

947

948

949

950

951

952

953

subsequently incubated with primary antibodies diluted in antibody blocking buffer for 2 hours at room temperature or overnight at $4{ }^{\circ} \mathrm{C}$. Detection was achieved using appropriate horseradish peroxidase (HRP)-conjugated secondary antibodies. Anti-SMARCAL1 (1:1000, Santa Cruz Biotechnology), antiBRCA1 (1:100, Santa Cruz Biotechnology) and anti-TUBULIN (1:50000, Abcam) antibodies were used in western blot experiments.

\section{Single-molecule analysis of DNA replication}

Exponentially growing MCF10A cells were pulse-labeled with $30 \mu \mathrm{M}$ CldU (25 minutes), washed and exposed to $150 \mu \mathrm{M}$ IdU (35 minutes). After exposure to the second nucleotide analog, the cells were washed again in warm 1x PBS and treated or not for 4 hours with hydroxyurea (HU, 2 mM, Sigma). Labeled cells were trypsinized and resuspended in ice-cold PBS at $4 \times 10^{5}$ cells $/ \mathrm{ml}$. Two microliters of this suspension were spotted onto a pre-cleaned glass slide and lysed with $10 \mu 1$ of spreading buffer (0.5\% SDS in $200 \mathrm{mM}$ Tris-HCl pH 7.4, 50 mM EDTA). After 6 minutes, the slides were tilted at $15^{\circ}$ relative to horizontal, allowing the DNA to spread. Slides were air-dried, fixed in methanol and acetic acid (3:1) for 2 minutes, rehydrated in PBS for 10 minutes and denatured with $2.5 \mathrm{M} \mathrm{HCl}$ for 50 minutes at room temperature. Slides were then rinsed in PBS and blocked in PBS + 0.1\% Triton X-100 (PBS$\mathrm{T})+5 \%$ BSA for 1 hour at room temperature. Rat anti-BrdU (1:100, Abcam) and mouse anti-BrdU $(1: 100, \mathrm{BD})$ were then applied to detect CldU and IdU, respectively. After 1 hour incubation, the slides were washed in PBS and stained with Alexa Fluor 488-labeled goat anti-mouse IgG1 antibody and Alexa Fluor 594-labeled goat anti-rat antibody (1:300 each, Thermo Fisher Scientific). Slides were mounted in Prolong Gold Antifade (Thermo Fisher Scientific) and held at $-20{ }^{\circ} \mathrm{C}$. Replication tracks were imaged on a Nikon Eclipse 90i microscope fitted with a PL Apo 40X/0.95 numerical aperture (NA) objective and measured using ImageJ software. In each experiment, 100 or more dual-labeled tracts were measured for fork degradation estimation.

\section{FUNDING}

This work was supported by the Swiss National Science Foundation [grant number 31003A_175444 to PC]; European Research Council [grant number 681630 to PC]; Swiss Cancer League [grant number KLS-4370-02-2018 to PC]; National Institutes of Health [grant numbers R01CA197774 and R01CA227450 to AC].

\section{DATA AVAILABILITY}

All primary data is available in this manuscript, supplementary information or source data. 


\section{ACKNOWLEDGEMENT}

956 We thank Massimo Lopes and Matteo Berti for sharing unpublished data and proving antibodies against

957 RAD51 paralogs, James T. Kadonaga for providing Topoisomerase I expression plasmid, Marcus The-

958 len for providing pBluescript II plasmid. We thank Elda Cannavo and Valentina Mengoli for comments

959 on the manuscript.

960

\section{CONFLICT OF INTEREST}

962 The authors declare that they have no conflict of interest.

963

\section{AUTHOR CONTRIBUTIONS}

965 S.H. performed most of the experiments, analyzed data, prepared figures. A.S. did some protection 966 assay with human RAD51. L.R. prepared RAD51. A.T. did in vivo studies with mutant SMARCAL1. 967 G.R., I.C., A.A. generated reagents for the study. R.A. performed preliminary protection experiments 968 with overhanged substrates. A.C. supervised A.T. for cellular studies using DNA fiber assay. P.C. con969 ceived, supervised and wrote the manuscript with input from S.H.

970

\section{$971 \quad$ FIGURE LEGENDS}

972 Figure 1. SMARCAL1, ZRANB3 and HLTF possess distinct biochemical activities

973 (a) Recombinant SMARCAL1, ZRANB3, and HLTF were analyzed by polyacrylamide gel electropho974 resis and stained with Coomassie Brilliant Blue.

975 (b) A schematic of replication fork reversal assay (leading and lagging strand gap structure is shown).

976 (c) Fork reversal assays with SMARCAL1, ZRANB3 and HLTF with RPA (3 nM). Top, quantifications 977 (error bars show SEM of three replicates); bottom, representative experiments.

978 (d) Fork reversal assays with HLTF without or with RPA (3 nM). Top, quantifications (error bars indi979 cate SEM of three replicates); bottom, representative experiments.

980 (e) A schematic of Holliday junction branch migration assay.

981 (f) Holliday junction branch migrations assay with SMARCAL1, ZRANB3 and HLTF. Top, quantifi982 cations (error bars indicate SEM of three replicates); bottom, representative experiments.

983 (g) A schematic of topoisomerase-coupled annealing assay.

984 (h) Comparison of SMARCAL1, ZRANB3 and HLTF in topoisomerase-coupled annealing assays. 985 ATP hydrolysis by HLTF is required, as no detectable annealing was observed without ATP. 
989 (a) A schematic of ssDNA annealing assays.

990 (b) Annealing of ssDNA by SMARCAL1, ZRANB3 and HLTF without or with RPA (4 nM). Repre991 sentative experiments are shown.

992 (c) Quantification of experiment as in (b) at 30 minutes (error bars indicate SEM of three replicates).

993 (d) Annealing of ssDNA by SMARCAL1 without or with human mitochondrial SSB (4 nM). Top, 994 quantifications (error bars indicate SEM of three replicates); bottom, representative experiments.

995 (e) Top, a schematic showing domain organization of SMARCAL1. RPA binding domain is located in 996 the N-terminal part of SMARCAL1 (indicated in dark blue). SMARCAL1 $\triangle \mathrm{N}$ lacking RPA binding 997 domain is shown below.

998 (f) Recombinant SMARCAL1-WT and SMARCAL1 $\triangle \mathrm{N}$ were analyzed by polyacrylamide gel electro999 phoresis and stained with Coomassie Brilliant Blue.

1000 (g) A comparison of SMARCAL1-WT and SMARCAL1 $\triangle \mathrm{N}$ in ssDNA annealing without or with RPA 1001 (4 nM). Top, quantifications (error bars indicate SEM of three replicates); bottom, representative ex1002 periments.

Figure 3. RAD51 and BCDX2 promote SMARCAL1 and ZRANB3 mediated branch migration and DNA annealing

(a) Recombinant RAD51 and BCDX2 were analyzed by polyacrylamide gel electrophoresis and stained with Coomassie Brilliant Blue.

1009 (b) Annealing helicase assay. RAD51 and BCDX2 separately stimulate SMARCAL1-mediated anneal-

1010 ing of RPA-coated ssDNA. Top, quantifications (error bars indicate SEM of four replicates); bottom, 1011 representative experiment. Statistical significance; $*(\mathrm{P}<0.05), * * *(\mathrm{P}<0.001)$, two-tailed t-test.

1012 (c) RAD51 and BCDX2 separately promote ZRANB3 mediated strand annealing. Top, quantifica-

1013 tions (error bars indicate SEM of four replicates); bottom, representative experiment. Statistical sig-

1014 nificance bars; $n s(\mathrm{P}>0.05$, not significant $)$ *** $(\mathrm{P}<0.01)$; two-tailed t-test.

1015 (d) RAD51 and BCDX2 do not promote HLTF-mediated DNA annealing. Shown is a representative 1016 experiment.

1018 Figure 4. SMARCAL1 and ZRANB3 physically interact with RAD51 and BCDX2

1019 (a) Soluble extract from E. coli containing MBP-RAD51 (bait) was immobilized on amylose resin and 1020 incubated with purified recombinant proteins (RAD51 paralogs, ZRANB3, SMARCAL1, [prey]) as 1021 indicated. Western blot analyses were performed with anti-MBP and anti-FLAG antibodies. 
1022 (b) and (c) Anti-His antibody was coupled to Protein G agarose, bound to the BCDX2 complex (bait) 1023 and tested for interaction with ZRANB3 (prey) or SMARCAL1 (prey), respectively. Samples were 1024 subjected to either silver staining or Western blot analysis by anti-FLAG and anti-His antibodies.

1025 (d) Multiple sequence alignment showing the presence of a consensus FxxA motif in SMARCAL1 1026 along with previously characterized RAD51 interacting proteins or BRCA2 domains (highlighted in 1027 grey with bold red letters).

1028 (e) Recombinant SMARCAL1-WT and SMARCAL1-F446A were analyzed by polyacrylamide gel 1029 electrophoresis and stained with Coomassie Brilliant Blue.

1030 (f) SMARCAL1-F446A fails to interact with RAD51. Soluble extract from E. coli containing MBP1031 RAD51 (bait) was immobilized on amylose resin and incubated with purified recombinant 1032 SMARCAL1 variants (prey). Ponceau staining shows RAD51. Western blot analysis was performed 1033 with anti-FLAG antibody to detect SMARCAL1.

1034 (g) SMARCAL1-F446A, as SMARCAL1-WT, interacts with the BCDX2 complex. Anti-His antibody 1035 was immobilized on protein G agarose, bound to BCDX2 complex (bait) and tested for interaction with 1036 SMARCAL1 variants (prey). Samples were subjected to silver staining.

1037 (h) DNA fiber assay to monitor SMARCAL1-mediated nascent DNA degradation in BRCA1-deficient 1038 cells. Wild type or SMARCAL1-F446A proteins were expressed in SMARCAL1 KO MCF10A cells 1039 upon BRCA1 depletion, as indicated. SMARCAL1-deficiency renders BRCA1-depleted cells resistant 1040 to replication fork degradation upon hydroxyurea (HU) treatment, as a result of impaired fork reversal. 1041 Top: a schematic of the assay: CldU (25 minutes), IdU (35 minutes) pulse-labeling protocol to evaluate 1042 fork degradation upon HU treatment. Under wild type condition the ratio of IdU/CldU tract length will 1043 remain $\sim 1$, however if there is fork degradation this ratio will be $<1$. Bottom: graphical representation 1044 of IdU/CIdU tract length ratio. The median value of 100 or more IdU and CldU tracts per experimental 1045 condition is indicated. Statistical analysis was conducted using Mann-Whitney test $(* * * * \mathrm{p}<0.0001)$. 1046 Data are representative of two independent experiments.

\section{Figure 5. RAD51 protects DNA from degradation by MRE11, EXO1 and DNA2 nucleases}

1050 (a) Top, a schematic of the assay. Bottom, endonuclease activity of MRN-pCtIP on quadruple blocked 1051 5'-end-labeled 70 bp-long dsDNA is efficiently inhibited by RAD51-WT and RAD51-K133R but not 1052 by RAD51-K133A, RAD51-Y232A or RAD51-T131P mutants. Reaction products were separated by $105315 \%$ denaturing polyacrylamide gel electrophoresis. In the schematic at the top, asterisk indicates the 1054 position of the radioactive label.

1055 (b) Quantification of experiments such as in panel (a) (error bars indicate SEM of three replicates).

1056 The level of DNA protection by RAD51 is presented as a relative value with respect to DNA degradation without RAD51 (lane 2 in panel a). 
1058 (c) Top, a schematic of the assay. Bottom, RAD51-WT and ATP-hydrolysis deficient K133R mutant 1059 efficiently protect DNA against the exonuclease activity of MR (MRE11-RAD50). RAD51 variants 1060 (RAD51-K133A, RAD51-Y232A or RAD51-T131P) with decreased DNA binding capacity failed to 1061 inhibit MR. 5'-end-labeled 50 bp-long dsDNA was used as a substrate. Asterisk indicates the position 1062 of the ${ }^{32} \mathrm{P}$ label. Reaction products were separated by $15 \%$ denaturing polyacrylamide gel electropho1063 resis.

1064 (d) Quantification of experiments such as shown in panel (c), error bars indicate SEM of three repli1065 cates. The level of DNA protection by RAD51 is presented as a relative value with respect to DNA 1066 degradation without RAD51 (lane 2 in panel c).

1067 (e) RAD51 efficiently protects against the exonuclease activity of MR on a 5'-end-labeled 50 bp-long 1068 dsDNA in presence of ATP. Reaction products were separated by $15 \%$ denaturing polyacrylamide gel 1069 electrophoresis. Top, quantifications (error bars indicate SEM of three replicates); bottom, a representa1070 tive experiment.

1071 (f) ATP-bound RAD51 efficiently protects against EXO1 on a 3'-end-labeled 50 bp-long dsDNA. Cal1072 cium (1 mM) traps ATP-bound RAD51 on DNA, which greatly enhances RAD51-mediated protection. 1073 Reaction products were separated by $15 \%$ denaturing polyacrylamide gel electrophoresis.

1074 (g) Quantifications of experiments such as in panel (f), error bars indicate SEM of at least three repli1075 cates.

1076 (h) Top, a schematic of the assay. Bottom, RAD51-WT and RAD51-K133R, but not RAD51-K133A 1077 variant efficiently protect against EXO1 degradation, using a 5'-end-labeled 50 bp-long dsDNA as a 1078 substrate. Asterisk indicates the position of the ${ }^{32} \mathrm{P}$ label. Reaction products were separated by $15 \%$ 1079 denaturing polyacrylamide gel electrophoresis.

1080 (i) Quantification of experiments such as shown in panel (h); error bars indicate SEM of three replicates. 1081 The level of DNA protection by RAD51 is presented as a relative value with respect to DNA degrada1082 tion without RAD51 (lane 2 in panel h).

1083 (j) Top, a schematic of the assay. Bottom, DNA degradation by WRN, DNA2 and RPA is inhibited by 1084 RAD51. 2.2-kilobase pair (kbp)-long randomly labeled dsDNA was used as the substrate. Reaction 1085 products were separated by $1 \%$ agarose gel electrophoresis. Red asterisks indicate random DNA label1086 ing.

1087 (k) Quantification of experiments such as shown in panel (j); error bars indicate SEM of three replicates. 1088 The level of DNA protection by RAD51 is presented as a relative value with respect to DNA degrada1089 tion without RAD51 (lane 4 in panel j).

1093 (a) Nuclease assays with MRE11-RAD50 (MR) and their inhibition by RAD51. The experiments were 1094 carried out with blunt-ended, 5'-overhanged or 3'-overhanged DNA. Asterisk indicates the position of 
1095 the labelling. Reaction products were separated by 15\% denaturing polyacrylamide gel electrophoresis.

1096 A representative experiment is shown.

1097 (b) Quantifications of experiments such as shown in panel (a), error bars indicate SEM of three repli1098 cates. The level of DNA protection by RAD51 is presented as a relative value with respect to DNA 1099 degradation for each substrate without RAD51 (lanes 3, 7 and 11 in panel a).

1100 (c) Nuclease assays with EXO1 and its inhibition by RAD51. Experiments were carried out with blunt1101 ended, 5'-overhanged or 3'-overhanged DNA. Asterisk indicates the position of the ${ }^{32} \mathrm{P}$ label. Reaction 1102 products were separated by $15 \%$ denaturing polyacrylamide gel electrophoresis. Shown is a representa1103 tive experiment.

1104 (d) Quantifications of experiments such as shown in panel (c), error bars indicate SEM of three repli1105 cates. The level of DNA protection by RAD51 is presented as a relative value with respect to DNA 1106 degradation for each substrate without RAD51 (lanes 2, 7 and 12 in panel c).

\section{Figure 7. Model for replication fork reversal and protection.}

1109 Fork remodelers have unequal biochemical functions. SMARCAL1 anneals RPA-coated ssDNA and 1110 may promote initial steps in fork reversal. ZRANB3 and HLTF are more proficient in branch migration.

1111 RAD51 and BCDX2 interact with SMARCAL1 and ZRANB3 and stimulate their activities. Reversed 1112 replication forks are prone to pathological degradation, in certain genetic backgrounds, unless protected 1113 by RAD51. We show that unexpectedly the dsDNA-binding capacity of RAD51 promotes DNA pro1114 tection against nucleases. 


\section{REFERENCES}

1122

1123

1124

1125

1126

1127

1128

1129

1130

1131

1132

1133

1134

1135

1136

1137

1138

1139

1140

1141

1142

1143

1144

1145

1146

1147

1148

1149

1150

1151

1152

1153

1154

1155

1156

1157

1158

1159

1160

1161

1162

1163

1164

1165

1166

1167

1168

1169
1. Ranjha L, Howard SM, Cejka P. Main steps in DNA double-strand break repair: an introduction to homologous recombination and related processes. Chromosoma 127, 187-214 (2018).

2. Kawale AS, Sung P. Mechanism and significance of chromosome damage repair by homologous recombination. Essays Biochem, (2020).

3. Anand R, Ranjha L, Cannavo E, Cejka P. Phosphorylated CtIP Functions as a Co-factor of the MRE11-RAD50-NBS1 Endonuclease in DNA End Resection. Mol Cell 64, 940950 (2016).

4. Reginato G, Cejka P. The MRE11 complex: A versatile toolkit for the repair of broken DNA. DNA Repair (Amst) 91-92, 102869 (2020).

5. Bonetti D, Colombo CV, Clerici M, Longhese MP. Processing of DNA Ends in the Maintenance of Genome Stability. Front Genet 9, 390 (2018).

6. Sigurdsson S, Van Komen S, Bussen W, Schild D, Albala JS, Sung P. Mediator function of the human Rad51B-Rad51C complex in Rad51/RPA-catalyzed DNA strand exchange. Genes Dev 15, 3308-3318 (2001).

7. Roy U, et al. The Rad51 paralog complex Rad55-Rad57 acts as a molecular chaperone during homologous recombination. Mol Cell, (2021).

8. Belan O, et al. Single-molecule analysis reveals cooperative stimulation of Rad51 filament nucleation and growth by mediator proteins. Mol Cell, (2021).

9. Schlacher K, Christ N, Siaud N, Egashira A, Wu H, Jasin M. Double-strand break repair-independent role for BRCA2 in blocking stalled replication fork degradation by MRE11. Cell 145, 529-542 (2011).

10. Hashimoto Y, Ray Chaudhuri A, Lopes M, Costanzo V. Rad51 protects nascent DNA from Mre11-dependent degradation and promotes continuous DNA synthesis. Nat Struct Mol Biol 17, 1305-1311 (2010).

11. Zeman MK, Cimprich KA. Causes and consequences of replication stress. Nat Cell Biol 16, 2-9 (2014).

12. Tirman S, et al. Temporally distinct post-replicative repair mechanisms fill PRIMPOLdependent ssDNA gaps in human cells. Mol Cell 81, 4026-4040 e4028 (2021).

13. Taglialatela A, et al. REV1-Polzeta maintains the viability of homologous recombination-deficient cancer cells through mutagenic repair of PRIMPOL-dependent ssDNA gaps. Mol Cell 81, 4008-4025 e4007 (2021).

14. Cortez D. Replication-Coupled DNA Repair. Mol Cell 74, 866-876 (2019). 
1170 15. Ray Chaudhuri A, et al. Topoisomerase I poisoning results in PARP-mediated

16. Berti M, Cortez D, Lopes M. The plasticity of DNA replication forks in response to clinically relevant genotoxic stress. Nat Rev Mol Cell Biol 21, 633-651 (2020).

17. Zellweger R, et al. Rad51-mediated replication fork reversal is a global response to genotoxic treatments in human cells. J Cell Biol 208, 563-579 (2015).

18. Sogo JM, Lopes M, Foiani M. Fork reversal and ssDNA accumulation at stalled replication forks owing to checkpoint defects. Science 297, 599-602 (2002).

19. Joseph SA, Taglialatela A, Leuzzi G, Huang JW, Cuella-Martin R, Ciccia A. Time for remodeling: SNF2-family DNA translocases in replication fork metabolism and human disease. DNA Repair (Amst) 95, 102943 (2020).

20. Neelsen KJ, Lopes M. Replication fork reversal in eukaryotes: from dead end to dynamic response. Nat Rev Mol Cell Biol 16, 207-220 (2015).

21. Ciccia A, et al. The SIOD disorder protein SMARCAL1 is an RPA-interacting protein involved in replication fork restart. Genes Dev 23, 2415-2425 (2009).

22. Ciccia A, et al. Polyubiquitinated PCNA recruits the ZRANB3 translocase to maintain genomic integrity after replication stress. Molecular cell 47, 396-409 (2012).

23. Yuan J, Ghosal G, Chen J. The annealing helicase HARP protects stalled replication forks. Genes Dev 23, 2394-2399 (2009).

24. Yuan J, Ghosal G, Chen J. The HARP-like domain-containing protein AH2/ZRANB3 binds to PCNA and participates in cellular response to replication stress. Mol Cell 47, 410-421 (2012).

25. Bansbach CE, Betous R, Lovejoy CA, Glick GG, Cortez D. The annealing helicase SMARCAL1 maintains genome integrity at stalled replication forks. Genes Dev 23, 2405-2414 (2009).

26. Weston R, Peeters H, Ahel D. ZRANB3 is a structure-specific ATP-dependent endonuclease involved in replication stress response. Genes Dev 26, 1558-1572 (2012).

27. Kolinjivadi AM, et al. Smarcal1-Mediated Fork Reversal Triggers Mre11-Dependent Degradation of Nascent DNA in the Absence of Brca2 and Stable Rad51 Nucleofilaments. Mol Cell 67, 867-881 e867 (2017).

28. Schlacher K, Wu H, Jasin M. A distinct replication fork protection pathway connects Fanconi anemia tumor suppressors to RAD51-BRCA1/2. Cancer Cell 22, 106-116 (2012).

29. Zadorozhny K, et al. Fanconi-Anemia-Associated Mutations Destabilize RAD51 Filaments and Impair Replication Fork Protection. Cell Rep 21, 333-340 (2017). 
30. Lemacon D, et al. MRE11 and EXO1 nucleases degrade reversed forks and elicit MUS81-dependent fork rescue in BRCA2-deficient cells. Nat Commun 8, 860 (2017).

31. Mijic S, et al. Replication fork reversal triggers fork degradation in BRCA2-defective cells. Nat Commun 8, 859 (2017).

32. Higgs MR, et al. BOD1L Is Required to Suppress Deleterious Resection of Stressed Replication Forks. Mol Cell 59, 462-477 (2015).

33. $\mathrm{Xu} \mathrm{S}$, et al. Abro1 maintains genome stability and limits replication stress by protecting replication fork stability. Genes Dev 31, 1469-1482 (2017).

34. Higgs MR, et al. Histone Methylation by SETD1A Protects Nascent DNA through the Nucleosome Chaperone Activity of FANCD2. Mol Cell 71, 25-41 e26 (2018).

35. Thangavel S, et al. DNA2 drives processing and restart of reversed replication forks in human cells. J Cell Biol 208, 545-562 (2015).

36. Taglialatela A, et al. Restoration of Replication Fork Stability in BRCA1- and BRCA2Deficient Cells by Inactivation of SNF2-Family Fork Remodelers. Mol Cell 68, 414430 e418 (2017).

37. Bhat KP, Cortez D. RPA and RAD51: fork reversal, fork protection, and genome stability. Nat Struct Mol Biol 25, 446-453 (2018).

38. Mason JM, Chan YL, Weichselbaum RW, Bishop DK. Non-enzymatic roles of human RAD51 at stalled replication forks. Nat Commun 10, 4410 (2019).

39. Berti $\mathrm{M}$, et al. Sequential role of RAD51 paralog complexes in replication fork remodeling and restart. Nat Commun 11, 3531 (2020).

40. Vujanovic M, et al. Replication Fork Slowing and Reversal upon DNA Damage Require PCNA Polyubiquitination and ZRANB3 DNA Translocase Activity. Mol Cell 67, 882-890 e885 (2017).

41. Betous R, et al. SMARCAL1 catalyzes fork regression and Holliday junction migration to maintain genome stability during DNA replication. Genes Dev 26, 151-162 (2012).

42. Betous R, Couch FB, Mason AC, Eichman BF, Manosas M, Cortez D. Substrateselective repair and restart of replication forks by DNA translocases. Cell Rep 3, 19581969 (2013).

43. Yusufzai T, Kadonaga JT. HARP is an ATP-driven annealing helicase. Science 322, 748-750 (2008).

44. Yusufzai T, Kadonaga JT. Annealing helicase 2 (AH2), a DNA-rewinding motor with an HNH motif. Proc Natl Acad Sci U S A 107, 20970-20973 (2010). 
45. Khadka P, Croteau DL, Bohr VA. RECQL5 has unique strand annealing properties relative to the other human RecQ helicase proteins. DNA Repair (Amst) 37, 53-66 (2016).

46. Garcia PL, Liu Y, Jiricny J, West SC, Janscak P. Human RECQ5beta, a protein with DNA helicase and strand-annealing activities in a single polypeptide. EMBO J 23, 2882-2891 (2004).

47. Mortensen UH, Bendixen C, Sunjevaric I, Rothstein R. DNA strand annealing is promoted by the yeast Rad52 protein. Proc Natl Acad Sci U S A 93, 10729-10734 (1996).

48. Sugiyama T, New JH, Kowalczykowski SC. DNA annealing by RAD52 protein is stimulated by specific interaction with the complex of replication protein A and singlestranded DNA. Proc Natl Acad Sci U S A 95, 6049-6054 (1998).

49. Berti M, et al. Human RECQ1 promotes restart of replication forks reversed by DNA topoisomerase I inhibition. Nat Struct Mol Biol 20, 347-354 (2013).

50. Masson JY, et al. Identification and purification of two distinct complexes containing the five RAD51 paralogs. Genes Dev 15, 3296-3307 (2001).

51. Somyajit K, Saxena S, Babu S, Mishra A, Nagaraju G. Mammalian RAD51 paralogs protect nascent DNA at stalled forks and mediate replication restart. Nucleic Acids Res 43, 9835-9855 (2015).

52. Rodrigue A, et al. Interplay between human DNA repair proteins at a unique doublestrand break in vivo. EMBO J 25, 222-231 (2006).

53. Scott DE, Marsh M, Blundell TL, Abell C, Hyvonen M. Structure-activity relationship of the peptide binding-motif mediating the BRCA2:RAD51 protein-protein interaction. FEBS Lett 590, 1094-1102 (2016).

54. Schwendener S, et al. Physical interaction of RECQ5 helicase with RAD51 facilitates its anti-recombinase activity. J Biol Chem 285, 15739-15745 (2010).

55. Matsuzaki K, Kondo S, Ishikawa T, Shinohara A. Human RAD51 paralogue SWSAP1 fosters RAD51 filament by regulating the anti-recombinase FIGNL1 AAA+ ATPase. Nat Commun 10, 1407 (2019).

56. Yuan J, Chen J. FIGNL1-containing protein complex is required for efficient homologous recombination repair. Proc Natl Acad Sci U S A 110, 10640-10645 (2013).

57. Piwko $\mathrm{W}$, et al. The MMS22L-TONSL heterodimer directly promotes RAD51dependent recombination upon replication stress. EMBO J 35, 2584-2601 (2016).

58. Pellegrini L, et al. Insights into DNA recombination from the structure of a RAD51BRCA2 complex. Nature 420, 287-293 (2002). 
59. Badu-Nkansah A, Mason AC, Eichman BF, Cortez D. Identification of a Substrate Recognition Domain in the Replication Stress Response Protein Zinc Finger Ran-

60. Symington LS. Mechanism and regulation of DNA end resection in eukaryotes. Critical reviews in biochemistry and molecular biology, 1-18 (2016).

61. Chi P, Van Komen S, Sehorn MG, Sigurdsson S, Sung P. Roles of ATP binding and ATP hydrolysis in human Rad51 recombinase function. DNA Repair (Amst) 5, 381-391 (2006).

62. Wang AT, et al. A Dominant Mutation in Human RAD51 Reveals Its Function in DNA Interstrand Crosslink Repair Independent of Homologous Recombination. Mol Cell 59, 478-490 (2015).

63. Matsuo Y, Sakane I, Takizawa Y, Takahashi M, Kurumizaka H. Roles of the human Rad51 L1 and L2 loops in DNA binding. FEBS J 273, 3148-3159 (2006).

64. Jensen RB, Carreira A, Kowalczykowski SC. Purified human BRCA2 stimulates RAD51-mediated recombination. Nature 467, 678-683 (2010).

65. Carreira A, et al. The BRC repeats of BRCA2 modulate the DNA-binding selectivity of RAD51. Cell 136, 1032-1043 (2009).

66. Esashi F, Galkin VE, Yu X, Egelman EH, West SC. Stabilization of RAD51 nucleoprotein filaments by the C-terminal region of BRCA2. Nat Struct Mol Biol 14, 468-474 (2007).

67. Cannavo E, Cejka P, Kowalczykowski SC. Relationship of DNA degradation by Saccharomyces cerevisiae exonuclease 1 and its stimulation by RPA and Mre11Rad50-Xrs2 to DNA end resection. Proc Natl Acad Sci U S A 110, E1661-1668 (2013).

68. Bai G, et al. HLTF Promotes Fork Reversal, Limiting Replication Stress Resistance and Preventing Multiple Mechanisms of Unrestrained DNA Synthesis. Mol Cell 78, 1237-1251 e1237 (2020).

69. Tian T, et al. The ZATT-TOP2A-PICH Axis Drives Extensive Replication Fork Reversal to Promote Genome Stability. Mol Cell 81, 198-211 e196 (2021).

70. Poole LA, Cortez D. Functions of SMARCAL1, ZRANB3, and HLTF in maintaining genome stability. Crit Rev Biochem Mol Biol 52, 696-714 (2017).

71. Taylor MR, et al. Rad51 Paralogs Remodel Pre-synaptic Rad51 Filaments to Stimulate Homologous Recombination. Cell 162, 271-286 (2015).

72. Liu J, Renault L, Veaute X, Fabre F, Stahlberg H, Heyer WD. Rad51 paralogues Rad55Rad57 balance the antirecombinase Srs 2 in Rad51 filament formation. Nature 479, 245 248 (2011). 
73. Serra H, Da Ines O, Degroote F, Gallego ME, White CI. Roles of XRCC2, RAD51B and RAD51D in RAD51-independent SSA recombination. PLoS Genet 9, e1003971 (2013).

74. Takata K, Reh S, Tomida J, Person MD, Wood RD. Human DNA helicase HELQ participates in DNA interstrand crosslink tolerance with ATR and RAD51 paralogs. Nat Commun 4, 2338 (2013).

75. Bhat KP, Krishnamoorthy A, Dungrawala H, Garcin EB, Modesti M, Cortez D. RADX Modulates RAD51 Activity to Control Replication Fork Protection. Cell Rep 24, 538545 (2018).

76. Benson FE, Stasiak A, West SC. Purification and characterization of the human Rad51 protein, an analogue of E. coli RecA. EMBO J 13, 5764-5771 (1994).

77. Sung P, Robberson DL. DNA strand exchange mediated by a RAD51-ssDNA nucleoprotein filament with polarity opposite to that of RecA. Cell 82, 453-461 (1995).

78. Kowalczykowski SC. An Overview of the Molecular Mechanisms of Recombinational DNA Repair. Cold Spring Harbor perspectives in biology 7, (2015).

79. Reginato G, Cannavo E, Cejka P. Physiological protein blocks direct the Mre11-Rad50Xrs2 and Sae2 nuclease complex to initiate DNA end resection. Genes Dev 31, 23252330 (2017).

80. Daza-Martin M, et al. Isomerization of BRCA1-BARD1 promotes replication fork protection. Nature 571, 521-527 (2019).

81. Howard SM, Ceppi I, Anand R, Geiger R, Cejka P. The internal region of CtIP negatively regulates DNA end resection. Nucleic Acids Res 48, 5485-5498 (2020).

82. Fyodorov DV, Kadonaga JT. Chromatin assembly in vitro with purified recombinant ACF and NAP-1. Methods Enzymol 371, 499-515 (2003).

83. Anand R, Pinto C, Cejka P. Methods to Study DNA End Resection I: Recombinant Protein Purification. Methods Enzymol 600, 25-66 (2018).

84. Pinto C, Kasaciunaite K, Seidel R, Cejka P. Human DNA2 possesses a cryptic DNA unwinding activity that functionally integrates with BLM or WRN helicases. Elife 5, (2016).

85. Anand R, et al. NBS1 promotes the endonuclease activity of the MRE11-RAD50 complex by sensing CtIP phosphorylation. EMBO J 38, (2019).

86. Ceppi I, et al. CtIP promotes the motor activity of DNA2 to accelerate long-range DNA end resection. Proc Natl Acad Sci U S A 117, 8859-8869 (2020).

87. Cannavo E, Reginato G, Cejka P. Stepwise 5' DNA end-specific resection of DNA breaks by the Mre11-Rad50-Xrs2 and Sae2 nuclease ensemble. Proc Natl Acad Sci U $S A$ 116, 5505-5513 (2019). 
88. Cannavo E, et al. Regulatory control of DNA end resection by Sae2 phosphorylation. Nat Commun 9, 4016 (2018).

89. Cannavo E, Cejka P. Sae2 promotes dsDNA endonuclease activity within Mre11Rad50-Xrs2 to resect DNA breaks. Nature 514, 122-125 (2014).

90. Pinto C, Anand R, Cejka P. Methods to Study DNA End Resection II: Biochemical Reconstitution Assays. Methods Enzymol 600, 67-106 (2018).

91. Gari K, Decaillet C, Stasiak AZ, Stasiak A, Constantinou A. The Fanconi anemia protein FANCM can promote branch migration of Holliday junctions and replication forks. Mol Cell 29, 141-148 (2008).

92. Cejka P, Kowalczykowski SC. The full-length Saccharomyces cerevisiae Sgs1 protein is a vigorous DNA helicase that preferentially unwinds holliday junctions. $J$ Biol Chem 285, 8290-8301 (2010).

93. Guarani V, Paulo J, Zhai B, Huttlin EL, Gygi SP, Harper JW. TIMMDC1/C3orf1 functions as a membrane-embedded mitochondrial complex I assembly factor through association with the MCIA complex. Mol Cell Biol 34, 847-861 (2014). 

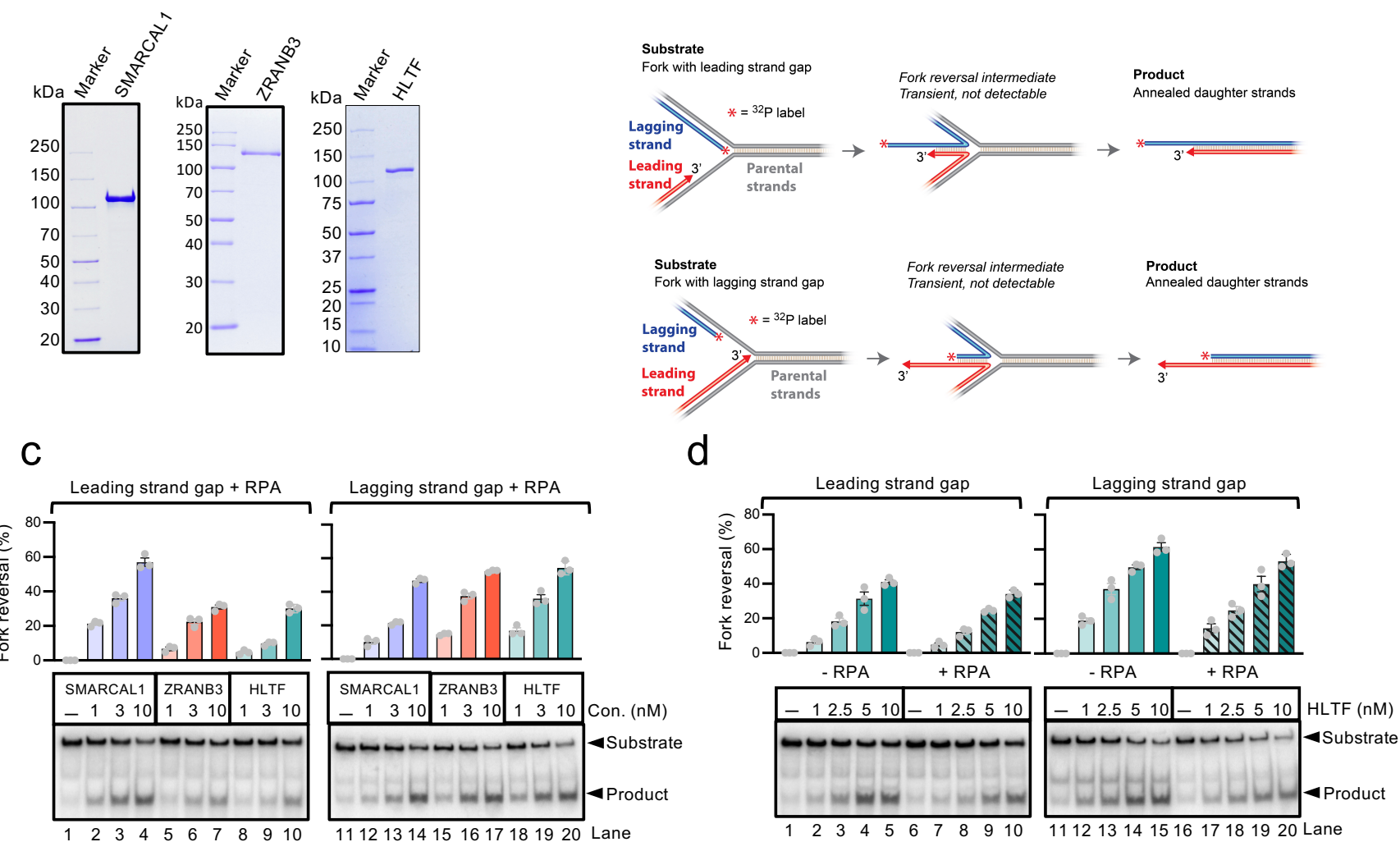

e
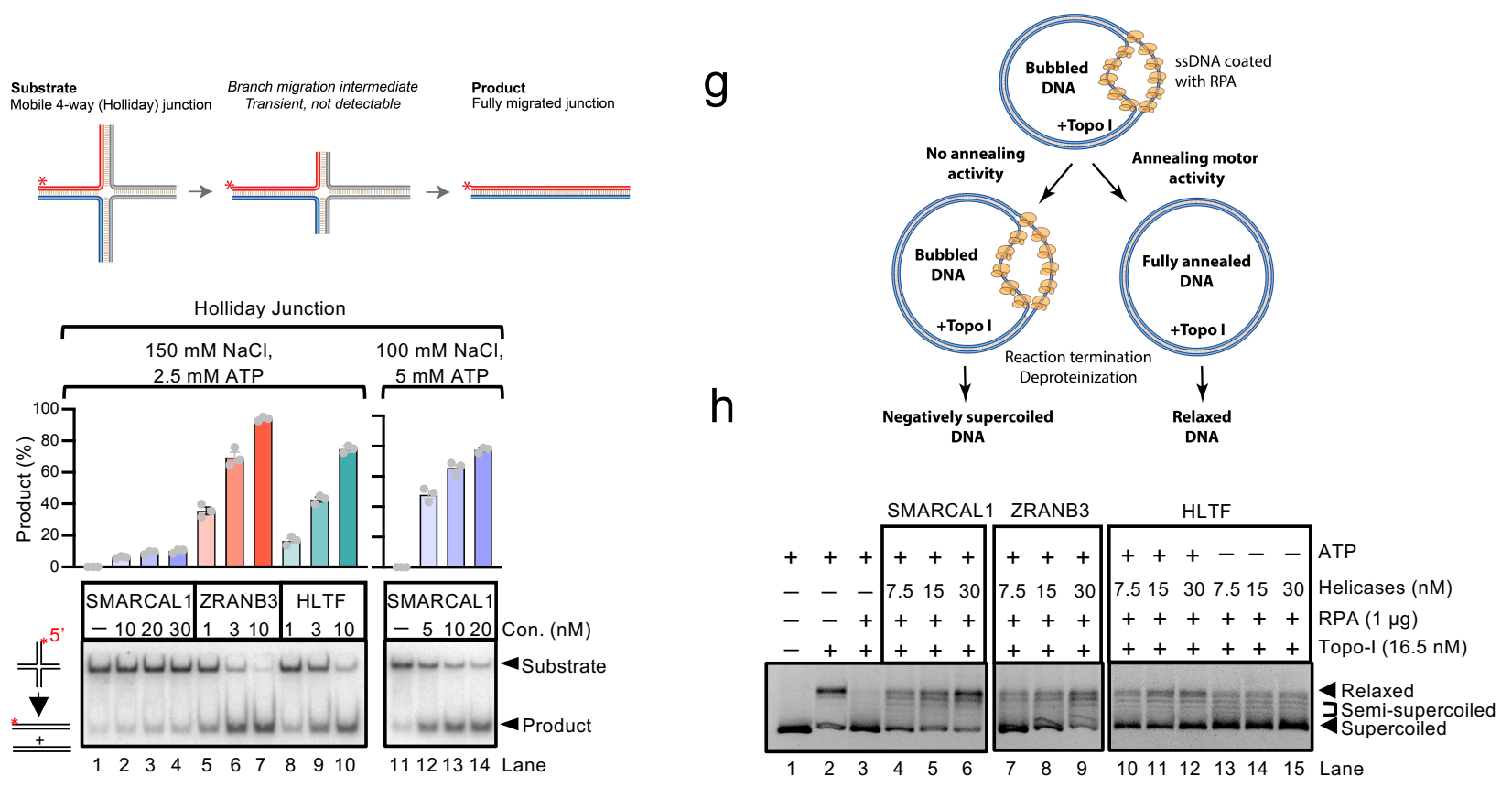

Figure 1. SMARCAL1, ZRANB3 and HLTF possess distinct biochemical activities

(a) Recombinant SMARCAL1, ZRANB3, and HLTF were analyzed by polyacrylamide gel electrophoresis and stained with Coomassie Brilliant Blue.

(b) A schematic of replication fork reversal assay (leading and lagging strand gap structure is shown).

(c) Fork reversal assays with SMARCAL1, ZRANB3 and HLTF. Top, quantifications (error bars show SEM of three replicates); bottom, representative experiments.

(d) Fork reversal assays with HLTF without or with RPA. Top, quantifications (error bars indicate SEM of three replicates); bottom, representative experiments.

(e) A schematic of Holliday junction branch migration assay.

(f) Holliday junction branch migrations assay with SMARCAL1, ZRANB3 and HLTF. Top, quantifications (error bars indicate SEM of three replicates); bottom, representative experiments.

(g) A schematic of topoisomerase-coupled annealing assay.

(h) Comparison of SMARCAL1, ZRANB3 and HLTF in topoisomerase-coupled annealing assays. ATP hydrolysis by HLTF is required, as no detectable annealing was observed without ATP. 
a

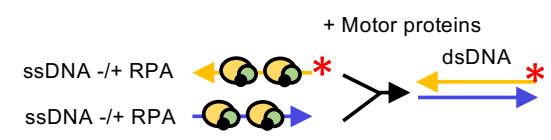

b

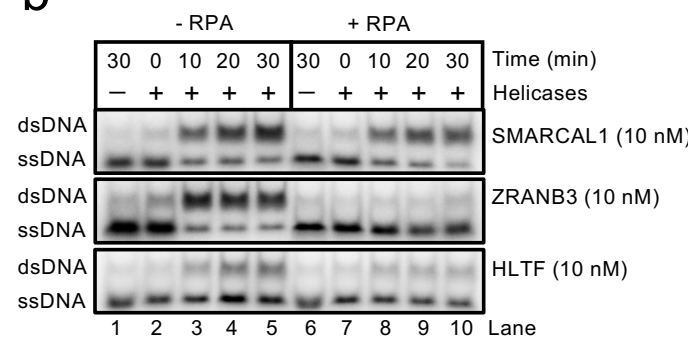

f

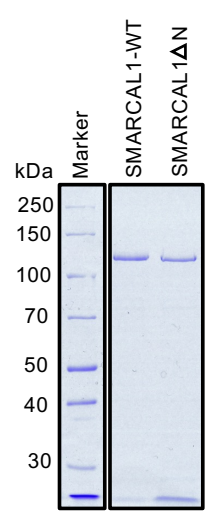

C

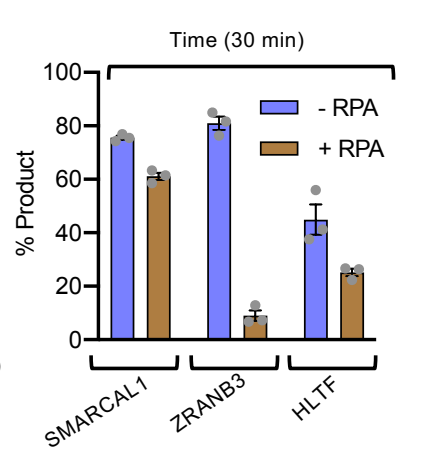

d

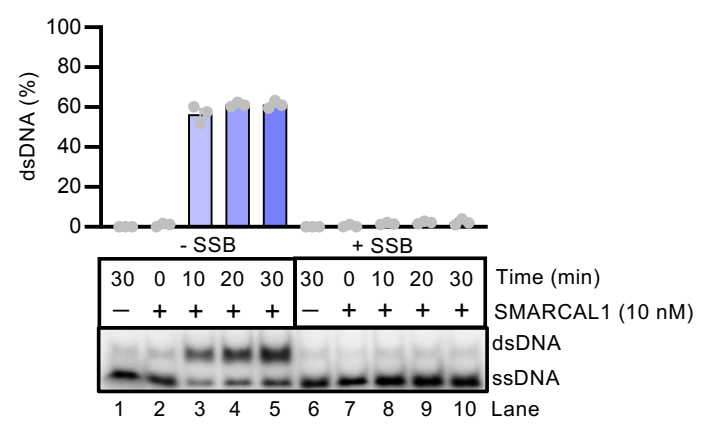

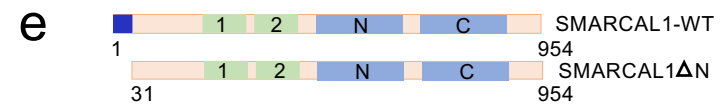

RPA Binding Domain (2-30)
1 HARP1 (226-303)
N ATPase_Nterm (445-600)

2 HARP2 (327-398)

C ATPase_Cterm (716-869)

g

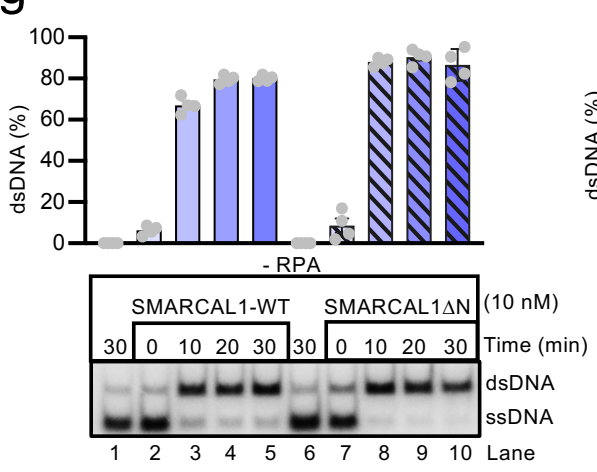

Figure 2. SMARCAL1 anneals RPA-coated SsDNA

(a) A schematic of ssDNA annealing assays.

(b) Annealing of ssDNA by SMARCAL1, ZRANB3 and HLTF without or with RPA. Representative experiments are shown.

(c) Quantification of (b) at 30 minutes (error bars indicate SEM of three replicates).

(d) Annealing of SSDNA by SMARCAL1 without or with human mitochondrial SSB. Top, quantifications (error bars indicate SEM of three replicates); bottom, representative experiments.

(e) Top, a schematic showing domain organization of SMARCAL1. RPA binding domain is located in the N-terminal part of SMARCAL1 (indicated in dark blue). SMARCAL1 $\triangle \mathrm{N}$ lacking RPA binding domain is shown below.

(f) Recombinant SMARCAL1-WT and SMARCAL1 $\triangle \mathrm{N}$ were analyzed by polyacrylamide gel electrophoresis and stained with Coomassie Brilliant Blue.

(g) A comparison of SMARCAL1-WT and SMARCAL1 $\triangle N$ in ssDNA annealing without or with RPA. Top, quantifications (error bars indicate SEM of three replicates); bottom, representative experiments. 
a

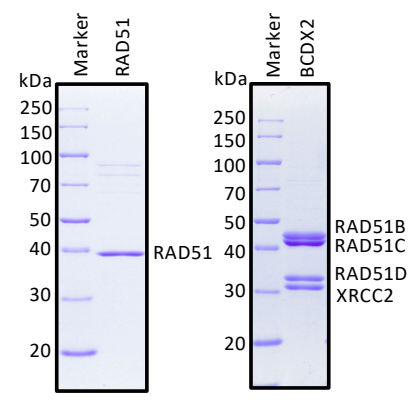

C

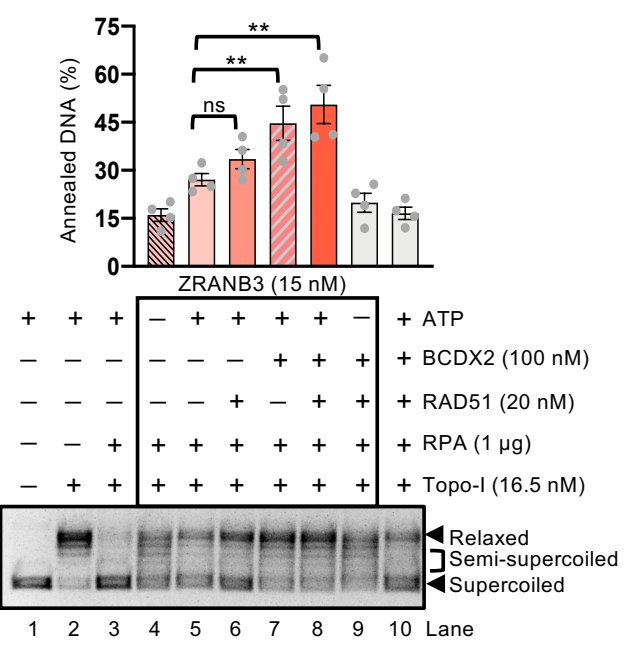

b

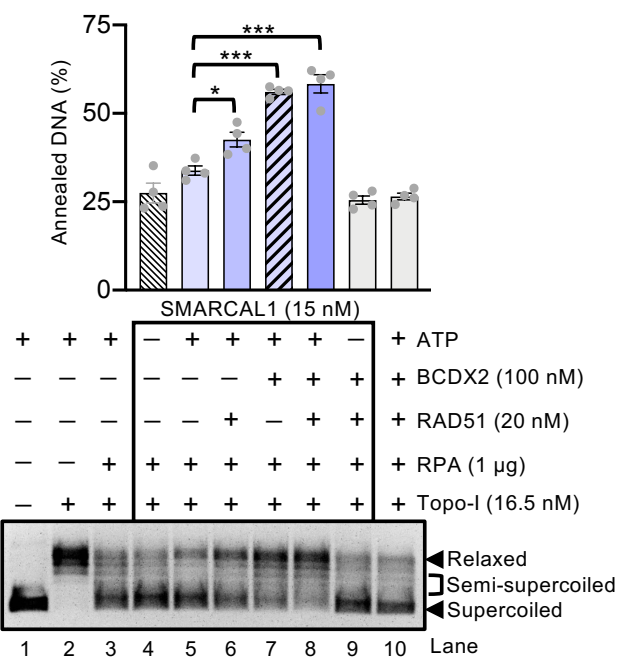

d

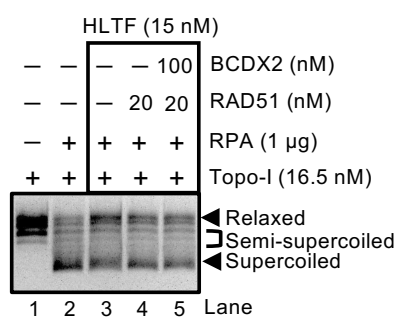

Figure 3. RAD51 and BCDX2 promote SMARCAL1 and ZRANB3 mediated bubble DNA annealing

(a) Recombinant RAD51 and BCDX2 were analyzed by polyacrylamide gel electrophoresis and stained with Coomassie Brilliant Blue.

(b) Annealing helicase assay. RAD51 and BCDX2 separately stimulate SMARCAL1-mediated annealing of RPA-coated ssDNA. Top, quantifications (error bars indicate SEM of four replicates); bottom, representative experiment. Statistical significance; ${ }^{*}(P<0.05)$, ${ }^{* *}(P<$ $0.001)$, two-tailed t-test.

(c) RAD51 and BCDX2 separately promote ZRANB3 mediated strand annealing. Top, quantifications (error bars indicate SEM of four replicates); bottom, representative experiment. Statistical significance bars; ns $\left(P>0.05\right.$, not significant); ${ }^{* *}(P<0.01)$; two-tailed t-test. (d) RAD51 and BCDX2 do not promote HLTF-mediated DNA annealing. Shown is a representative experiment. 

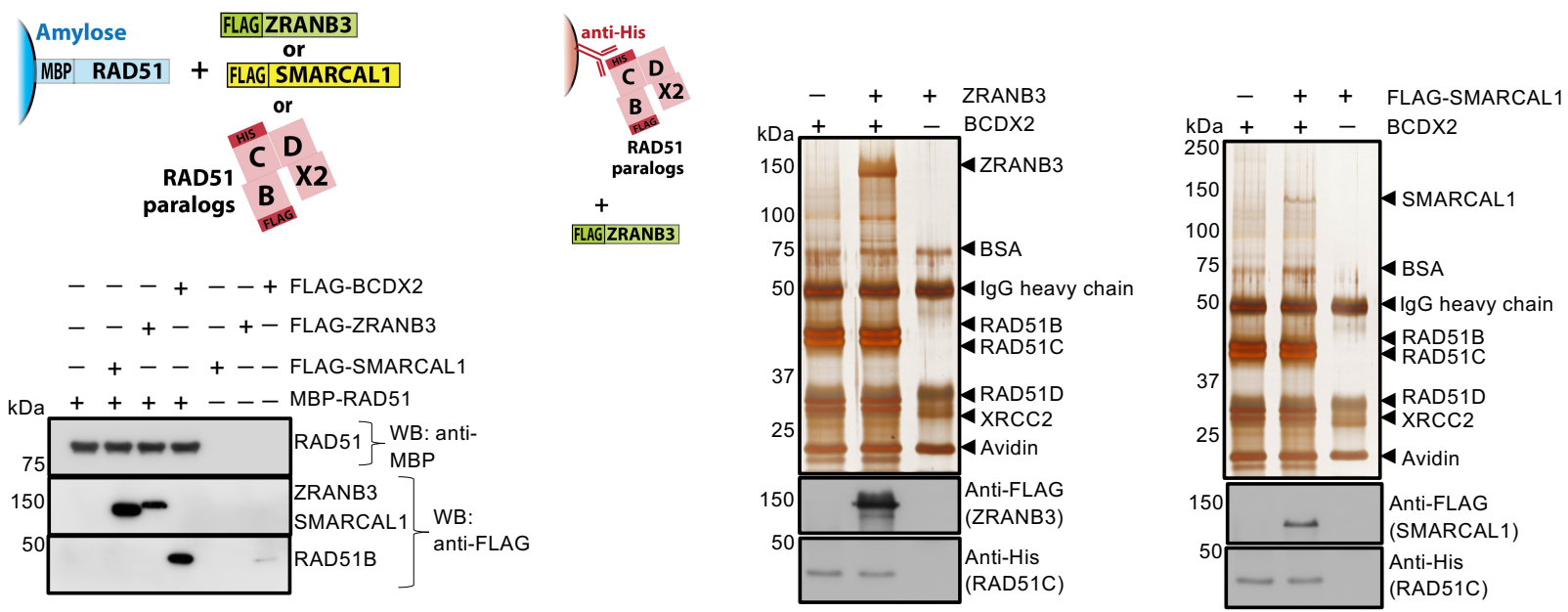

d

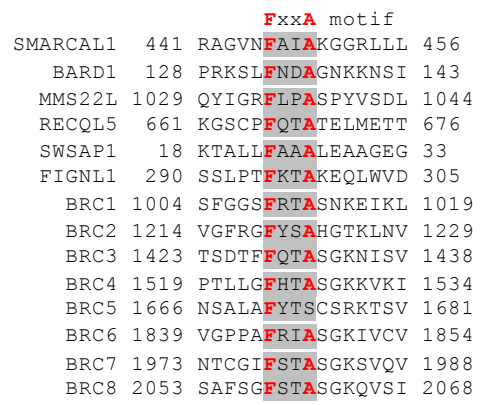

9
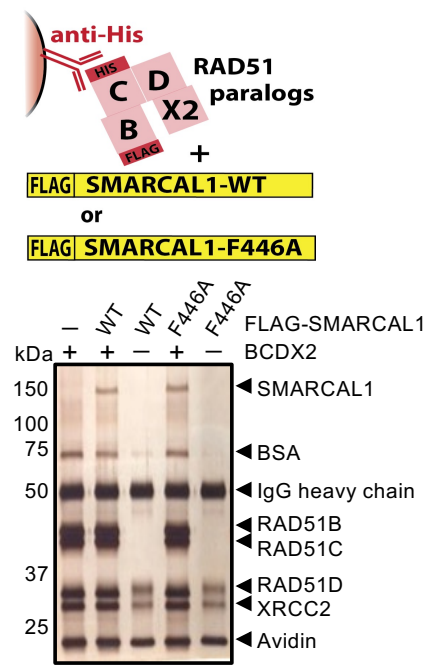

e

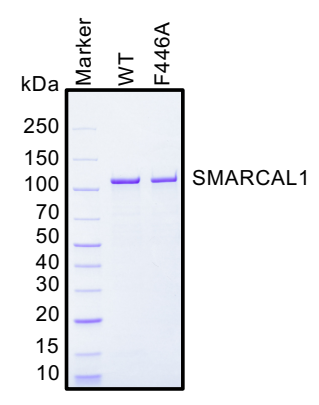

f
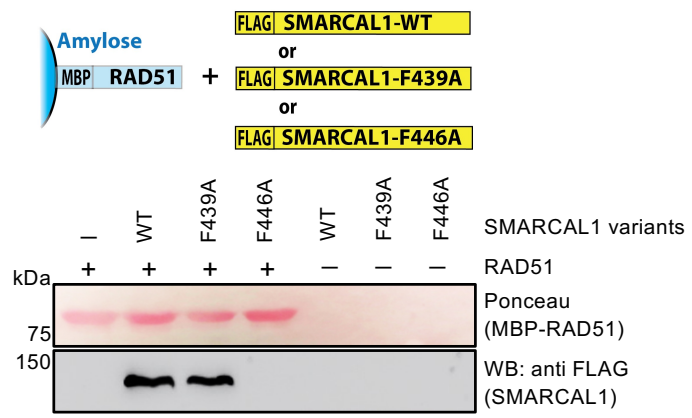

h

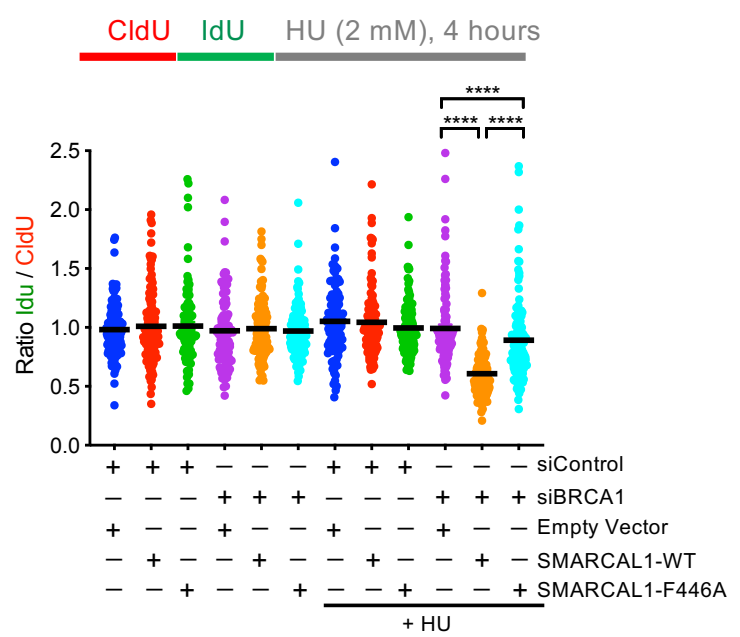

Figure 4. SMARCAL1 and ZRANB3 physically interact with RAD51 and BCDX2

(a) Soluble extract from E. coli containing MBP-RAD51 (bait) was immobilized on amylose resin and incubated with purified recombinant proteins (RAD51 paralogs, ZRANB3, SMARCAL1, [prey]) as indicated. Western blot analyses were performed with anti-MBP and anti-FLAG antibodies.

(b) and (c) Anti-His antibody was coupled to Protein G agarose, bound to the BCDX2 complex (bait) and tested for interaction with ZRANB3 (prey) or SMARCAL1 (prey), respectively. Samples were subjected to either silver staining or Western blot analysis by anti-FLAG and anti-His antibodies.

(d) Multiple sequence alignment showing the presence of a consensus FxxA motif in SMARCAL1 along with previously characterized RAD51 interacting proteins or BRCA2 domains (highlighted in grey with bold red letters).

(e) Recombinant SMARCAL1-WT and SMARCAL1-F446A were analyzed by polyacrylamide gel electrophoresis and stained with Coomassie Brilliant Blue.

(f) SMARCAL1-F446A fails to interact with RAD51. Soluble extract from E. coli containing MBP-RAD51 (bait) was immobilized on amylose resin and incubated with purified recombinant SMARCAL1 variants (prey). Ponceau staining shows RAD51. Western blot analysis was performed with anti-FLAG antibody to detect SMARCAL1.

(g) SMARCAL1-F446A, as SMARCAL1-WT, interacts with the BCDX2 complex. Anti-His antibody was immobilized on protein G agarose, bound to BCDX2 complex (bait) and tested for interaction with SMARCAL1 variants (prey). Samples were subjected to silver staining.

(h) DNA fiber assay to monitor SMARCAL1-mediated nascent DNA degradation in BRCA1-deficient cells. Wild type or SMARCAL1-F446A proteins were expressed in SMARCAL1 KO MCF10A cells upon BRCA1 depletion, as indicated. SMARCAL1-deficiency renders BRCA1-depleted cells resistant to replication fork degradation upon hydroxyurea (HU) treatment, as a result of impaired fork reversal. Top: a schematic of the assay: CldU (25 minutes), IdU (35 minutes) pulse-labeling protocol to evaluate fork degradation upon $\mathrm{HU}$ treatment. Under wild type condition the ratio of IdU/CldU tract length will remain $\sim 1$, however if there is fork degradation this ratio will be < 1. Bottom: graphical representation of IdU/CldU tract length ratio. The median value of 100 or more IdU and CldU tracts per experimental condition is indicated. Statistical analysis was conducted using Mann-Whitney test $\left({ }^{* \star *} \mathrm{p}<0.0001\right)$. Data are representative of two independent experiments. 
a

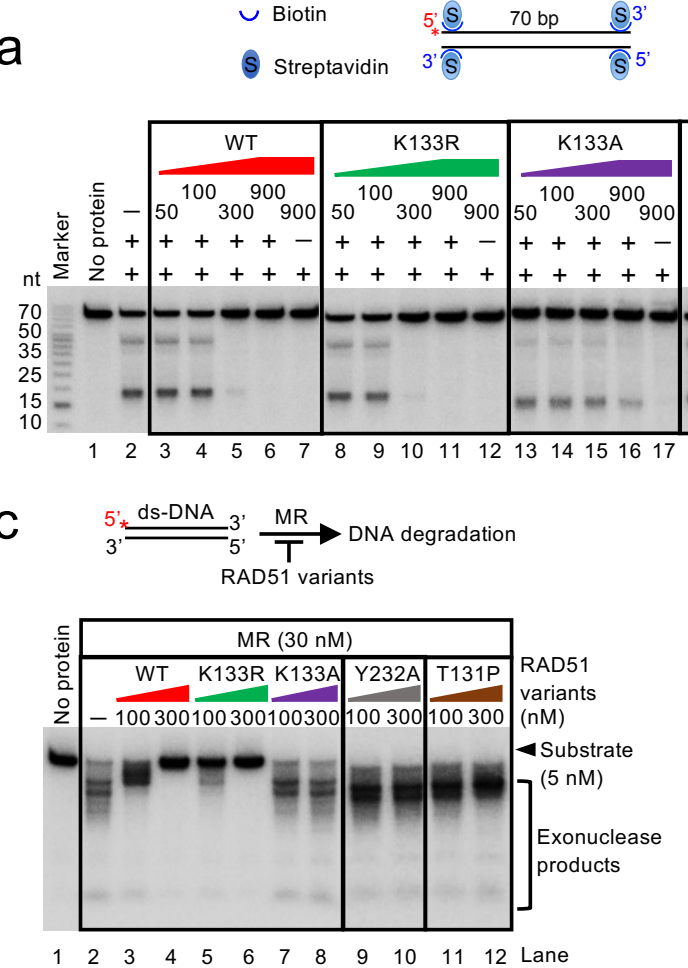

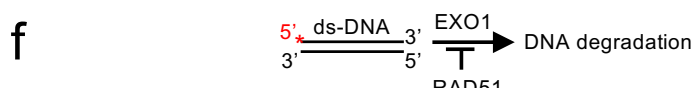

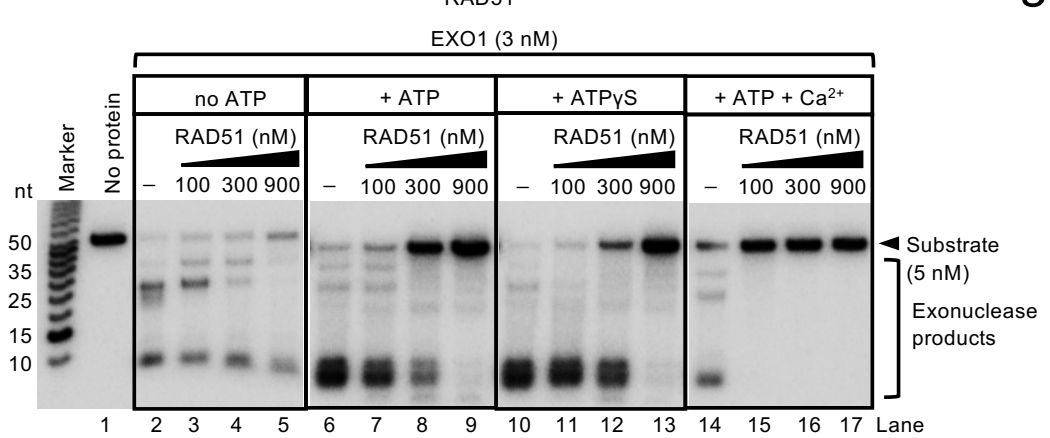

b

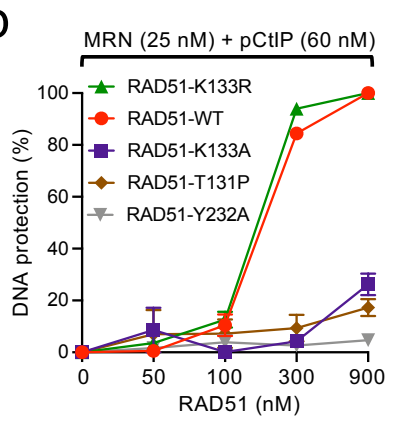

d

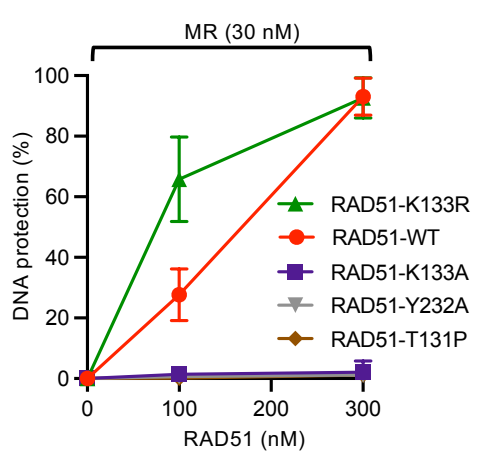

e

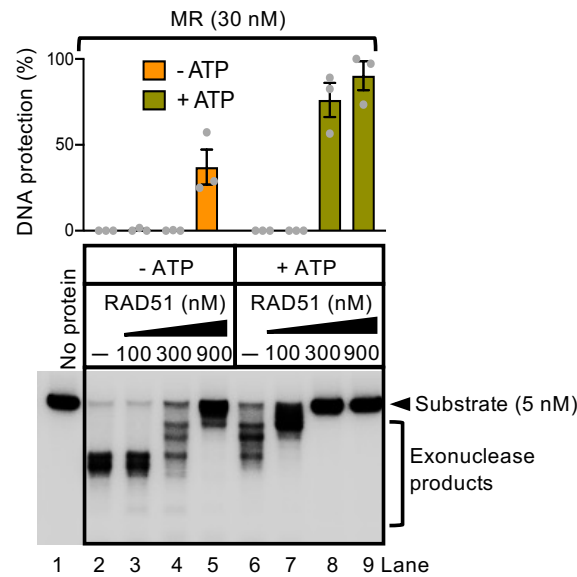

EXO1

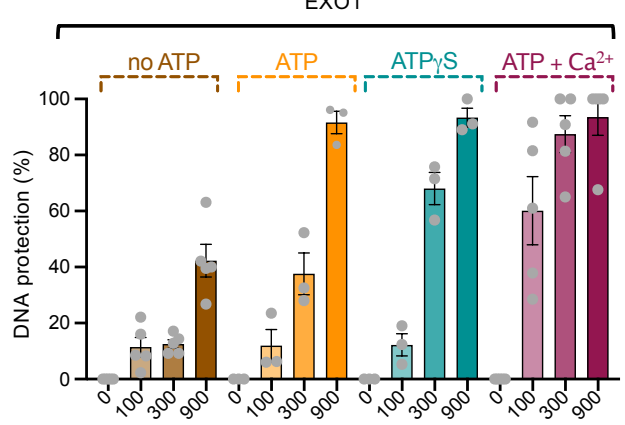

RAD51 (nM)

$\mathrm{h}$

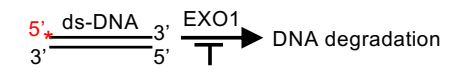

RAD51 variants

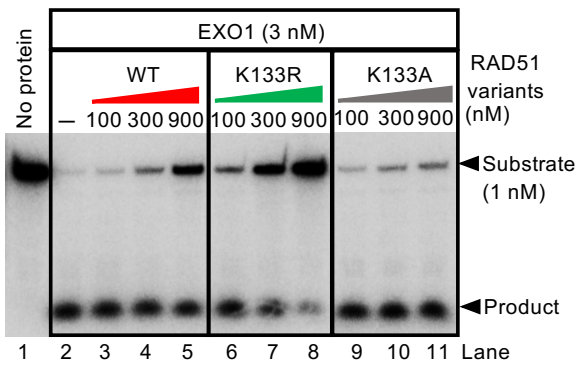

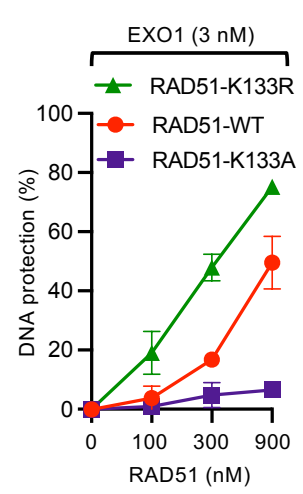

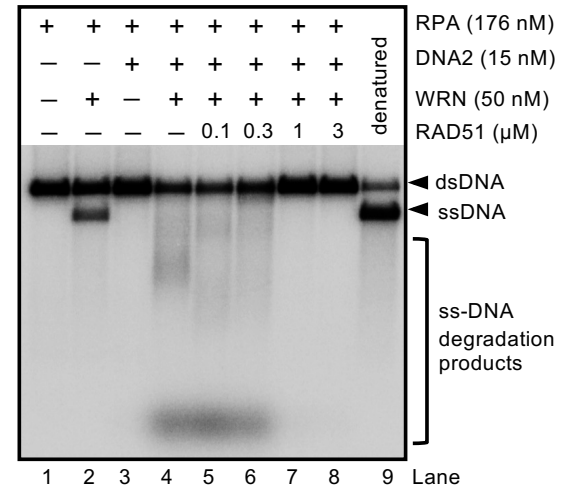

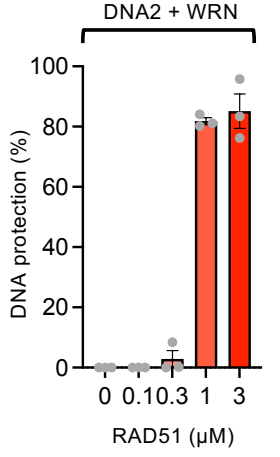

Figure 5. RAD51 protects DNA from degradation by MRE11, EXO1 and DNA2 nucleases

(a) Top, a schematic of the assay. Bottom, endonuclease activity of MRN-pCtIP on quadruple blocked 5'-end-labeled 70 bp-long dsDNA is efficiently inhibited by RAD51-WT and RAD51-K133R but not by RAD51-K133A, RAD51-Y232A or RAD51-T131P mutants. Reaction products were separated by 15\% denaturing polyacrylamide gel electrophoresis. In the schematic at the top, asterisk indicates the position of the radioactive label.

(b) Quantification of experiments such as in panel (a) (error bars indicate SEM of three replicates). The level of DNA protection by RAD51 is presented as a relative value with respect to DNA degradation without RAD51 (lane 2 in panel a). 
(c) Top, a schematic of the assay. Bottom, RAD51-WT and ATP-hydrolysis deficient K133R mutant efficiently protect DNA against the exonuclease activity of MR (MRE11-RAD50). RAD51 variants (RAD51-K133A, RAD51-Y232A or RAD51-T131P) with decreased DNA binding capacity failed to inhibit MR. 5'-end-labeled 50 bp-long dsDNA was used as a substrate. Asterisk indicates the position of the ${ }^{32} \mathrm{P}$ label. Reaction products were separated by $15 \%$ denaturing polyacrylamide gel electrophoresis.

(d) Quantification of experiments such as shown in panel (c), error bars indicate SEM of three replicates. The level of DNA protection by RAD51 is presented as a relative value with respect to DNA degradation without RAD51 (lane 2 in panel c).

(e) RAD51 efficiently protects against the exonuclease activity of MR on a 5'-end-labeled 50 bp-long dsDNA in presence of ATP. Top, quantifications (error bars indicate SEM of three replicates); bottom, a representative experiment.

(f) ATP-bound RAD51 efficiently protects against EXO1 on a 5'-end-labeled 50 bp-long dsDNA. Calcium (1 mM) traps ATP-bound RAD51 on DNA, which greatly enhances RAD51-mediated protection.

(g) Quantifications of experiments such as in panel (f), error bars indicate SEM of at least three replicates.

(h) Top, a schematic of the assay. Bottom, RAD51-WT and RAD51-K133R, but not RAD51-K133A variants efficiently protect against EXO1 degradation, using a 5'end-labeled 50 bp-long dsDNA as a substrate. Asterisk indicates the position of the ${ }^{32} \mathrm{P}$ label. Reaction products were separated by $15 \%$ denaturing polyacrylamide gel electrophoresis.

(i) Quantification of experiments such as shown in panel (h); error bars indicate SEM of three replicates. The level of DNA protection by RAD51 is presented as a relative value with respect to DNA degradation without RAD51 (lane 2 in panel h).

(j) Top, a schematic of the assay. Bottom, DNA degradation by WRN, DNA2 and RPA is inhibited by RAD51. 2.2-kilobase pair (kbp)-long randomly labeled dsDNA was used as the substrate. Reaction products were separated by $1 \%$ agarose gel electrophoresis. Red asterisks indicate random DNA labeling.

(k) Quantification of experiments such as shown in panel (j); error bars indicate SEM of three replicates. The level of DNA protection by RAD51 is presented as a relative value with respect to DNA degradation without RAD51 (lane 4 in panel j). 
a

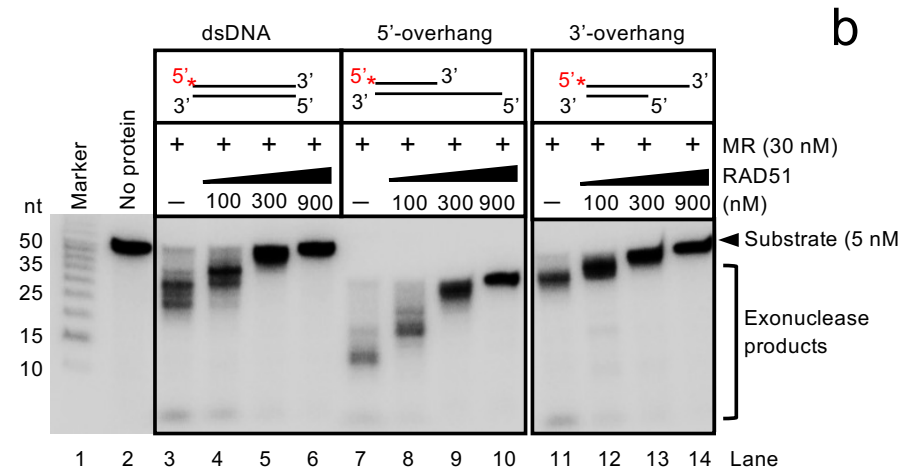

C

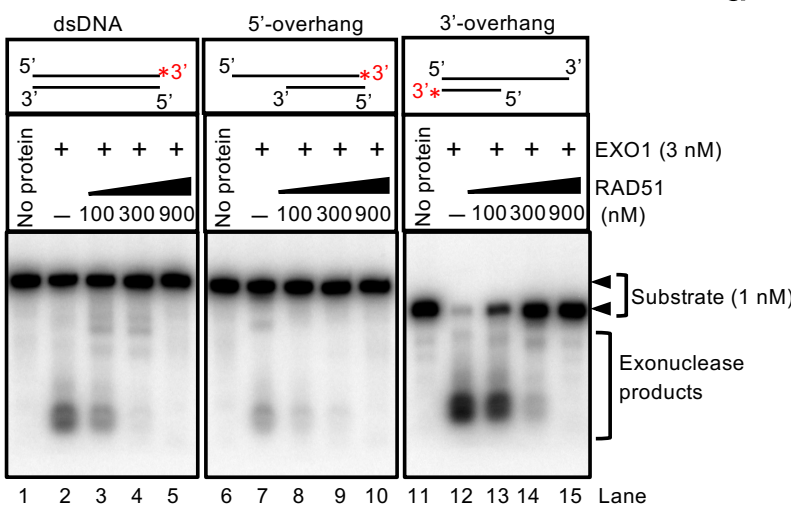

MR (30 nM)
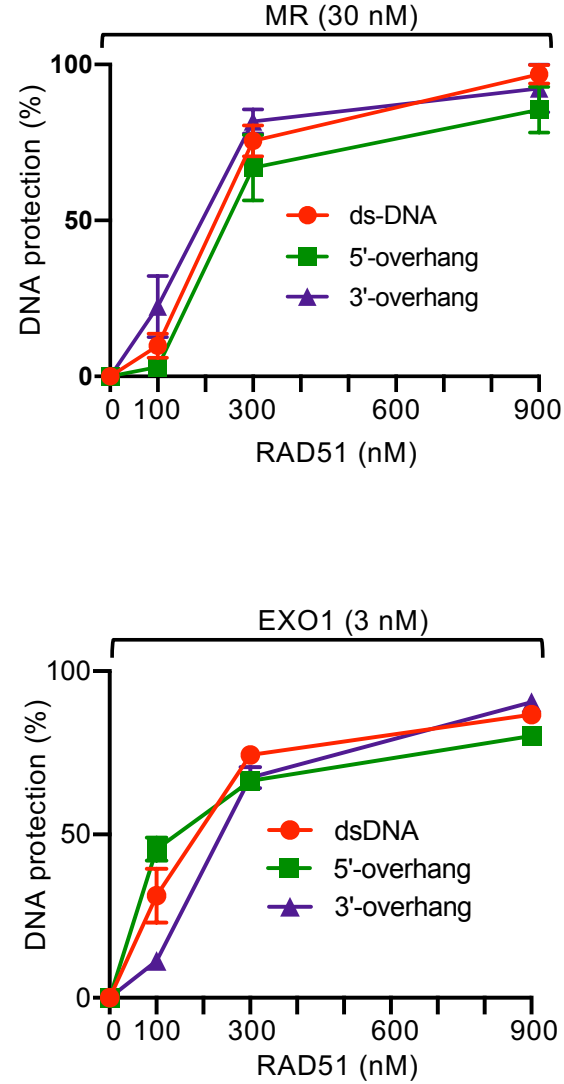

Figure 6. Nucleolytic degradation is prevented by RAD51 upon binding to dsDNA

(a) Nuclease assays with MRE11-RAD50 (MR) and their inhibition by RAD51. The experiments were carried out with blunt-ended, 5'overhanged or 3 '-overhanged DNA. Asterisk indicates the position of the labelling. Reaction products were separated by $15 \%$ denaturing polyacrylamide gel electrophoresis. A representative experiment is shown.

(b) Quantifications of experiments such as shown in panel (a), error bars indicate SEM of three replicates. The level of DNA protection by RAD51 is presented as a relative value with respect to DNA degradation for each substrate without RAD51 (lanes 3,7 and 11 in panel a).

(c) Nuclease assays with EXO1 and its inhibition by RAD51. Experiments were carried out with blunt-ended, 5'-overhanged or 3'overhanged DNA. Asterisk indicates the position of the ${ }^{32} \mathrm{P}$ label. Reaction products were separated by $15 \%$ denaturing polyacrylamide gel electrophoresis. Shown is a representative experiment.

(d) Quantifications of experiments such as shown in panel (c), error bars indicate SEM of three replicates. The level of DNA protection by RAD51 is presented as a relative value with respect to DNA degradation for each substrate without RAD51 (lanes 2,7 and 12 in panel c). 


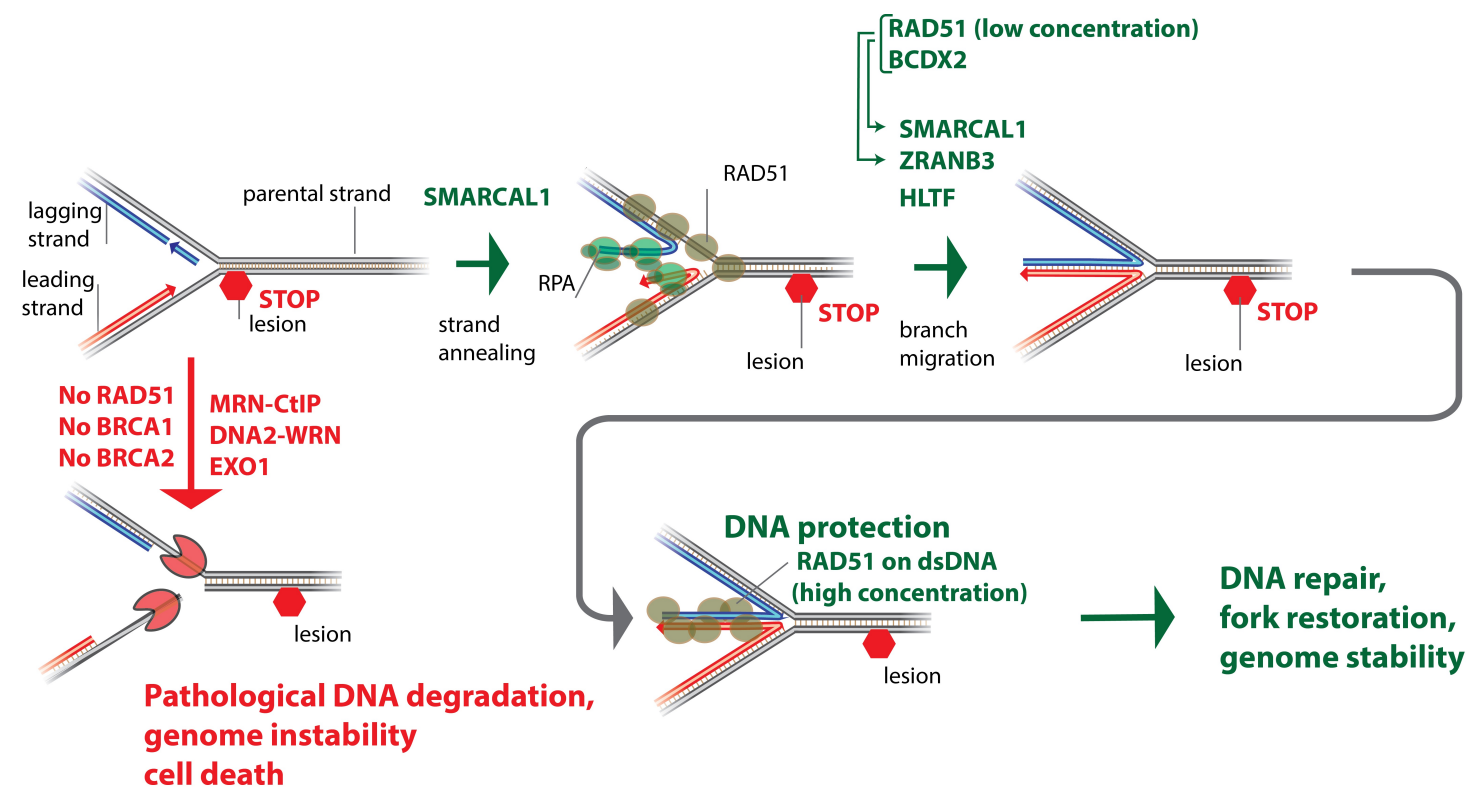

Figure 7. Model for replication fork reversal and protection.

Fork remodelers have unequal biochemical functions. SMARCAL1 anneals RPA-coated ssDNA and may promote initial steps in fork reversal. ZRANB3 and HLTF are more proficient in branch migration. RAD51 and BCDX2 interact with SMARCAL1 and ZRANB3 and promote their activities. Reversed replication forks are prone to pathological degradation, in certain genetic backgrounds, unless protected by RAD51. We show that unexpectedly the dsDNA-binding capacity of RAD51 promotes DNA protection against nucleases. 


\section{Supplementary Files}

This is a list of supplementary files associated with this preprint. Click to download.

- HalderSupplementarylnformation.pdf

- Halderreportingsummaryflatten.pdf 